University of Rhode Island

DigitalCommons@URI

Open Access Master's Theses

1991

\title{
Biology of Lebia subgrandis Madge, A Natural Enemy of the Colorado Potato Beetle
}

\author{
Eduardo Aranda \\ University of Rhode Island
}

Follow this and additional works at: https://digitalcommons.uri.edu/theses

\section{Recommended Citation}

Aranda, Eduardo, "Biology of Lebia subgrandis Madge, A Natural Enemy of the Colorado Potato Beetle" (1991). Open Access Master's Theses. Paper 1372.

https://digitalcommons.uri.edu/theses/1372

This Thesis is brought to you for free and open access by DigitalCommons@URI. It has been accepted for inclusion in Open Access Master's Theses by an authorized administrator of DigitalCommons@URI. For more information, please contact digitalcommons-group@uri.edu. 
BIOLOGY OF Lebia subgrandis Madge, A NATURAL ENEMY OF THE COLORADO POTATO BEETLE

By

EDUARDO ARANDA

A THESIS SUBMITTED IN PARTIAL FULFILLMENT OF THE REQUIREMENTS FOR THE DEGREE OF MASTER OF SCIENCE

IN

PLANT PATHOLOGY / ENTOMOLOGY

UNIVERSITY OF RHODE ISLAND

1991 


\section{MASTER OF SCIENCE THESIS \\ OF

\author{
EDUARDO ARANDA
}

\section{APPROVED:}

Thesis Committee

Major Professor

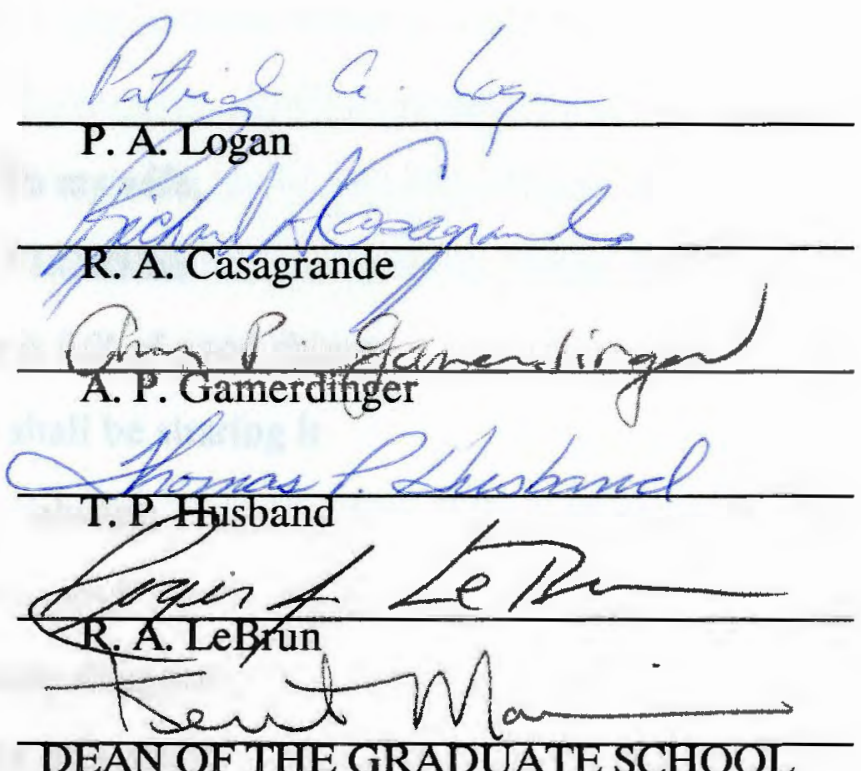

\section{UNIVERSITY OF RHODE ISLAND}


To my wife,

\section{FLOREN:}

Our future is full of good things

and we shall be sharing it

always;

and

To my daughter,

ANA FLOREN:

It is through the shining of your eyes

that I have found the peace in my mind

and my happiness. 


\title{
BIOLOGY OF Lebia subgrandis Madge, A NATURAL ENEMY OF THE COLORADO POTATO BEETLE
}

\begin{abstract}
I investigated the biology of the Mexican carabid, Lebia subgrandis Madge, a potential biological control agent of the Colorado Potato Beetle (CPB), Leptinotarsa decemlineata (Say). The consumption of CPB eggs and 1st through 3rd instar larvae increased with temperature for both male and female $L$. subgrandis. Under laboratory conditions, confined pairs consumed up to 108 CPB eggs / day at $28^{\circ} \mathrm{C}$ (mean $=44.5 \mathrm{CPB}$ eggs $/$ day). Early-summer females produced more offspring than late-summer females. Apparently, mating was infrequent; I found no difference in oviposition rates when the females were confined with males for $0,1,2$, or 3 days, or for the entire experiment. First instar L. subgrandis larvae lived an average of 8.3 days. They are ectoparasites of CPB prepupae and pupae and actively seek their hosts in the soil.

Adult $L$. subgrandis seek their prey both day and night. The host range is narrow: previously starved or not, this species refused eggs and larvae of Coleomegilla maculata DeGeer, and eggs and nymphs of either Oplomus sp. or a reduviid predator. Adults lived four to five months. Reproductive capacity was temperature dependent. L. subgrandis might be considered as a candidate to control the CPB in the northeast U.S.
\end{abstract}




\section{ACKNOWLEDGMENTS}

I thank Dr. Patrick Logan, my major professor. He opened a door and gave me the chance to learn to be a scientist. The many talks, thoughts, and experiences shared with him have shaped my thinking towards future work in entomology. I always found words of support, friendship, and encouragement from him.

I also thank Dr. Richard Casagrande and Dr. Roger LeBrun for providing help to keep the research going. I thank Dr. Thomas Husband and Dr. Amy Gamerdinger for reading and providing many helpful comments on my thesis. I thank Dr. Richard Hull and the Department of Plant Sciences for support. I am grateful to Dr. Carl Beckman for his friendship from the moment I met him. I thank Wenhua $\mathrm{Lu}$ for long hours of help with the experiments and for her friendship.

I thank Dr. Cesar Garcia Montalvo for allowing me the time to come to Rhode Island, and for his moral support and friendship.

I thank Idalia Cuevas, Carlos Romero, and Guillermo Aldama for their help in 1988 and 1989. I thank Jesus "Tele" Hernandez and Irma Alarcon for the excellent field and lab work they did during the summer of 1990 . We are all committed to improve entomology in Morelos and Mexico.

Most of all I thank my best friend Flore for coping with my impatient character and for giving a purpose to my life.

Kingston, Rhode Island.

February 1991. 


\section{TABLE OF CONTENTS}

INTRODUCTION 1

Chemical controls 1

$\begin{array}{ll}\text { Cultural controls } & 1\end{array}$

Biological controls $\quad 2$

METHODS AND MATERIALS $\quad 6$

Field investigations $\quad 6$

Collections $\quad 6$

$\begin{array}{ll}\text { Observation areas } & 7\end{array}$

Effect of plant height, plant density, and foliar

density on the incidence of $L$. subgrandis $\quad 7$

$\begin{array}{ll}\text { Nightly activity of } L \text {. subgrandis } & 7\end{array}$

Field emergence of $L$. subgrandis $\quad 8$

$\begin{array}{ll}\text { Laboratory experiments } & 8\end{array}$

Food preference using Mexican CPB $\quad 8$

Consumption rate using R.I. CPB 9

Host specificity of adult L. subgrandis $\quad 10$

Oviposition by L. subgrandis $\quad 12$

Seasonality of $L$. subgrandis fecundity, I $\quad 12$

Seasonality of L. subgrandis fedundity, II 13

Survival of $L$ subgrandis first instar larvae $\quad 13$

Development of ovaries in L. subgrandis $\quad 13$

$\begin{array}{ll}\text { Overwintering of adult } L \text {. subgrandis } & 14\end{array}$

Survival of field-collected adult L. subgrandis $\quad 14$ 
RESULTS

Field investigations

Effect of plant height, plant density, and foliar

density on the incidence of $L$. subgrandis

Nightly activity of $L$. subgrandis

Field emergence of $L$. subgrandis

Laboratory experiments

Food preference using Mexican CPB

Consumption rate using R.I. CPB

Host specificity of adult $L$. subgrandis

Oviposition of $L$. subgrandis

Seasonality of $L$. subgrandis fecundity, I

Seasonality of $L$. subgrandis fecundity, II

Survival of $L$. subgrandis first instar larvae

Development of ovaries in L. subgrandis

Overwintering of adult $L$. subgrandis

Survival of field-collected adult $L$. subgrandis

Miscellaneous observations 


\section{LIST OF TABLES}

1. Biological control agents of the CPB, with references.

2. Coefficients of determination $\left(R^{2}\right)$ and equations for linear regressions between totals of Lebia subgrandis (Y) and CPB life stages (X).

3. Effect of plant height, density, and foliar density on

CPB egg, larval, and adult and Lebia subgrandis adult incidence (number per plant), July 11 to

August 24, 1990. (Mean \pm s.d., $N=11$ plants).

4. Three-way ANOVA for consumption of RI CPB by Lebia subgrandis.

5. Simple effects test for the interaction of sex grouping of Lebia subgrandis and stage of CPB offered, by temperature.

6. Coefficients of the general linear model for CPB consumption by L. subgrandis (female, male, and pairs).

7. Daily consumption of CPB by L. subgrandis, by temperature. 


\section{LIST OF FIGURES}

1. Number of adult CPB's per plant (-- - - ) and adult

Lebia subgrandis per plant (— Chiverias site $(7 / 3 / 90$ to $8 / 17 / 90)$ and Tequesquitengo site $(8 / 20 / 91$ to 9/21/91), Morelos, Mexico.

2. Number of adult Lebia subgrandis recorded at night at the Chiverias site (7/29/91 and 8/26/91). All active adults were recorded visually over a $30 \mathrm{~min}$. observation period every 2 hours.

3. Observed (- $\longrightarrow$ ) and predicted (-..-) daily consumption of CPB prey by female Lebia subgrandis.

4. Observed (—_ $)$ and predicted (- - - - ) daily consumption of CPB prey by male Lebia subgrandis.

5. Observed (— $\longrightarrow$ ) and predicted (- - - - daily consumption of CPB prey by pairs of Lebia subgrandis. 
The Colorado Potato Beetle (CPB), Leptinotarsa decemlineata (Say) (Coleoptera: Chrysomelidae), is the most destructive pest of potato crops in North America and Europe (Gimingham 1950, Gauthier et al. 1981, Casagrande 1987, Groden 1989, Hare 1990) and it has been the object of many control efforts.

Chemical controls. The first attempts to control the CPB used products like tobacco water, coal tar mixed with water, lime sulphur, ashes, and white hellebore. These failed. The first reported success came with the discovery of the insecticidal properties of Paris green (copper acetoarsenite). After 1865, Paris green was used widely (Casagrande 1987). Following Paris green, growers have used a wide variety of chemical insecticides (Gimingham 1950, Gauthier et al. 1981, Casagrande 1987). The CPB has developed resistance to most of these chemicals (Cutkomp et al. 1958; Gauthier et al. 1981; Harris and Svec 1981; Forgash 1981, 1985; Argentine et al. 1989; Hare 1990). Efforts to deter the CPB from feeding on potato foliage by using fungicides reduced CPB populations (Hare et al. 1983, Hare 1984). Drummond and Casagrande (1985) reported that tannins extracted from white oak bark and leaves also inhibit the CPB from feeding on potato foliage.

Cultural controls. Before Paris green, growers attempted to control the CPB by hand-picking, using pinchers, and through predation by turkeys (Casagrande 1987). Since 1980, attention has again focused on alternative management strategies. Casagrande (1987) and Hare (1990) reviewed cultural practices used to manage CPB populations. In the Soviet Union, Sorokin (1981) and Koval (1986) cited several studies concerning potato cultural that enhance populations of predatory carabids. 
Biological controls. Studies in biological control of the CPB are summarized in Table 1, with selected references. Interest in biological control is reflected in the number of studies begun in the 1980's. Thus far, no single natural enemy has proven by itself to provide significant control of the CPB.

In the Soviet Union, the carabid beetles Carabus hampei, Poecilus cupreus, and Pterostichus melanarius have been studied as natural enemies of the CPB (Koval 1986). Sorokin (1981) recorded 14 species of carabids that feed on all stages of the CPB. He found that the most efficient species were Pterostichus cupreus, Ophonus rufipes, and Broschus cephalotes. However, there is not enough evidence that most of the agents mentioned might be used on a large scale to regulate CPB populations. Most of the natural enemies investigated are limited in one way or another in their abilities to control the CPB.

Because Central Mexico is considered to be the evolutionary home of the genus Leptinotarsa (Tower 1906), several researchers have made field trips to this region to search for natural enemies suitable as biocontrols of the CPB. There are no reports of carabids from these trips (Logan et al. 1987). Galindo (1990) lists natural enemies of $L$. decemlineata collected within the municipality of Cuernavaca (northern Morelos). She does not report lebiine carabids in her paper, but repeats most of the predators and parasites previously reported by Cappaert (1989).

Beginning in 1987, extensive field studies in Mexico suggested the importance of ground beetles as possible biocontrol agents of the CPB. Cappaert (1989) surveyed predators and parasites of the CPB in the State of Morelos during 1987 and 1988. He recorded seven species of carabids that feed on CPB eggs and larvae, but did not evaluate their potential for biological control. Little information is available about the biology of these species. In collections made from early May 
Table 1. Biological control agents of the CPB, with selected references.

Agent

Fungus

Beauveria bassiana

Bacteria

Bacillus thuringiensis

Protozoa (Microsporidians)

Nosema equestris

Nosema gastroidea

Acari

Chrysomelobia labidomerae

Arachnida

Phalangium opilio
Reference

Saminakova et al. 1981; Clark et al. 1982; Ignoffo et al. 1983; Campbell et

al. 1985; Anderson et al. 1988, 1989;

Loria et al. 1983; Watt and LeBrun 1984; Hajek et al. 1987.

Cantwell and Cantelo 1981, 1984;

Cantwell et al. 1983; Ignoffo et al.

1982; Ferro and Gelertner 1989;

Zehnder and Gelertner 1989.

Hostounsky 1984.

Drummond 1986, 1988; Drummond et al. 1984a, 1985, 1988, 1989.

Drummond et al. 1990. 
Table 1. (continued)

Agent

Hymenoptera

Edovum puttleri

Diptera

Tachinidae

Hemiptera

Perillus bioculatus

Oplomus dichrous

Coleoptera

Coccinellidae

Coleomegilla maculata

Carabidae

Lebia grandis

\section{Reference}

Corrigan 1988; Grisell 1981; Idoine and Ferro 1989; Jansson et al. 1987;

Lashomb et al. 1987a,b; Ruberson et al. 1988.

Tamaki et al. 1983a,b; Drummond et al. 1984b, 1987.

Tamaki and Butt 1978.

Drummond et al. 1987.

Groden et al. 1990.

Groden 1989; Hemenway and

Whitcomb 1967; Chamboussou 1939;

Trouvelot 1931. 
through mid-July in 1988, and late August 1989, I collected seven more species of carabids. Lebia subgrandis Madge was present in my collections. This species appears to be an abundant natural enemy of the CPB in Morelos. In this study, I investigated the biology of $L$. subgrandis, and assessed its potential to become a biological control agent of the CPB in Rhode Island. 


\section{METHODS AND MATERIALS}

\section{Field Investigations}

Collections. During the early summer of 1990 , I looked for suitable places within the State of Morelos to observe L. subgrandis. Most of the places I found were below $1000 \mathrm{~m}$ above sea level. A few sites were up to $1500 \mathrm{~m}$ and these were mostly within the municipalities of Cuernavaca and Tepoztlan. In all sites I collected CPB in all life stages, as well as foliage of its host plants, and carabids.

Cappaert (1990) reported that the principle host plant for the CPB in Morelos is Solanum angustifolium. Whalen (1979) listed 13 closely related species within the series Androceras, based on collections in the vicinity of Morelos. His list included both $S$. angustifolium and $S$. rostratum. The host plants from which I collected CPB's most resembled Whalen's descriptions of $S$. rostratum. Exact taxonomic determination of the host plants could not be made: I will use the term Solanum sp. to refer to the host plants.

I collected carabids by trapping them between the top and bottom of a plastic petri dish. To transport the insects to the lab, I used cartons filled with foliage. Without foliage, the carabids were likely to display a defensive mechanism that could kill the insects in seconds (See Miscellaneous observations, below).

Sweep nets and pitfall traps were useless for collecting adequate numbers of L. subgrandis. Because this species usually moves from plant to plant through foliage, I also set five to ten "aerial" pitfall traps on three occasions. The traps consisted of one liter plastic containers topped with a plastic funnel that fitted exactly. The funnel was kept in place using tape. I baited the traps with CPB larvae on Solanum sp. foliage, and placed them in the main branches of the plant. 
Observation areas. Two sites were suitable to conduct the observations: Chiverias and Tequesquitengo (Municipality of Jojutla). Due to the small area and irregular shape of both sites, I chose one plot of 5 X $5 \mathrm{~m}$ in each site. I counted all host plants and adult CPB's on 10 plants, and all adult $L$. subgrandis inside each plot. Initially, the plan was to count the adult CPB's in $10 \%$ of the host plants, but some of the plants were so small that I never observed adult CPB's on them. These plants were excluded from subsequent observations.

Effect of plant height, plant density, and foliar density on the incidence of $L$. subgrandis. Flagged Solanum sp. plants were used to evaluate the impact of plant size, foliar density, and plant spacing on the number of adult $L$. subgrandis. Outside each plot and at both sites, I flagged seven Solanum sp. plants as follows: three plants by height -- large $(>60 \mathrm{~cm})$, medium $(40-60 \mathrm{~cm})$, or small $(<40 \mathrm{~cm})$; two plants by foliar density -- plentiful or sparse; and two plant sets by spacing -grouped or isolated. Within each category, other characteristics were fixed. For height, I used plants with plentiful foliage within grouped plants. Medium-sized plants within groups were used for foliar density. In the spacing study, I used medium-sized plants with plentiful foliage. A linear regression analysis was performed with the totals of $L$. subgrandis regressed over the totals of each stage of the CPB in each plant category. I selected other sites to collect adult $L$. subgrandis for laboratory trials and to collect CPB eggs and larvae used for food.

Nightly activity of $L$. subgrandis. I conducted nightly observations to observe the activity of $L$. subgrandis. Adult carabids were spotted using a flashlight directed to the plants by intervals of 20 to 30 seconds. I counted the $L$. subgrandis present on and around all Solanum within and area of approximately 10 sq. m. (including the 
plot used during the day). Groden (1989) used this method to count L. grandis on potatos in RI, and with good results. The count was repeated every two hours, from 6 p.m. to 10 a.m. the next day. I considered as active those insects visibly present on the plants a performing defined behaviors: searching, foraging, walking, mating, fighting, or flying. Those insects found under rocks or hidden in crevices were not considered as active.

Field emergence of $L$. subgrandis. To estimate the emergence of $L$. subgrandis in the field, I placed five to ten emergence cages on both the Chiverias and Tequesquitengo sites. The cages consisted of a $50 \times 50 \times 15.5$ (height) $\mathrm{cm}$ wooden frame, made of $2 \mathrm{~cm}$ thick boards, covered with fine plastic mesh on top. The cages were in place most of the study until I retired them (except for six, which were stolen).

\section{Laboratory experiments}

L. subgrandis beetles were sexed using the preapical notch on the mesotibia of males (Madge 1967). The insects were grouped with four or five individuals per dish (males or females), and kept at room temperatures $\left(22-26^{\circ} \mathrm{C}\right)$.

Food preference using Mexican CPB. To test if $L$. subgrandis prefers a particular CPB stage, I conducted choice trials at room temperatures $\left(22-26^{\circ} \mathrm{C}\right)$ at the Laboratorio de Entomologia of the Universidad de Morelos, Mexico. I offered four stages of CPB as food (eggs, 1st, 2nd, and 3rd instar larvae), always in excess and within the same dish. The food was placed on Solanum sp. foliage. I deleted fourth instar larvae from the study because in previous trials (Aranda, unpublished data) $L$. subgrandis refused to eat 4 th instars even when starved. Eight individual carabid females and males, as well as eight pairs (female/male) randomly selected 
from the lab colony, were placed in plastic petri dishes with the bottom covered by a $2 \mathrm{~mm}$ layer of local soil. I recorded the consumption of each stage, removed the residues, and added new food to each dish daily for five days. An Analysis of Variance (PROC GLM, SAS Institute 1990) was used to estimate differences in the consumption rate of $L$. subgrandis due to preference for a specific CPB stage or due to L. subgrandis grouping (i.e., males, females, pairs).

Consumption rate using RI CPB. To determine the effect of temperature on rates of $L$. subgrandis consumption of RI CPB, temperatures of 13,16, 19, 22, 25, and $28^{\circ} \mathrm{C}$ were set in growth chambers with a photoperiod of $\mathrm{L}: \mathrm{D}=16: 8$. The consumption rate was taken to be the number of CPB eggs, first, second, or third instar larvae consumed by a pair or by individual $L$ subgrandis per day at each temperature. I offered each stage of CPB separately and always in excess. The insects were placed in plastic petri dishes: The bottom of the dishes was covered with a $2 \mathrm{~mm}$ layer of five parts of vermiculite and one part of fine sand. I recorded the consumption rate at each temperature for every CPB stage offered, removed the residues, and added new food to each dish daily. The trials were not made inorder of temperatures or CPB stage but rather were conducted as food or growth chamber space became available. Those beetles that died during the trial were replaced with new individuals and the experiment was then repeated using that insect. The experiments were run for an average of seven days. An Analysis of Variance (PROC GLM, SAS Institute 1990) was used to estimate the influence of CPB stage, sex grouping, and temperature upon the consumption rate by $L$. subgrandis. The linear model used in the GLM procedure was:

$$
Y=B_{0}+B_{1} X_{1}+B_{2} X_{2}+B_{3} X_{3}+B_{4} X_{1} X_{2}+B_{5} X_{1} X_{3}+B_{6} X_{2} X_{3}+B_{7} X_{1} X_{2} X_{3}
$$


where $\mathrm{Y}$ is the daily consumption rate,

$\mathrm{X}_{1}$ is the temperature,

$\mathrm{X}_{2}$ is the stage of CPB offered as food, and

$\mathrm{X}_{3}$ is the sex grouping (i.e., males, females, pairs).

Host specificity of adult $L$. subgrandis. All trials were performed in $90 \mathrm{~mm}$ plastic petri dishes lined with moistened paper towel. I placed the dishes in a growth chamber set at $25^{\circ} \mathrm{C}$ at the greenhouse at URI and at room temperature $\left(22-26^{\circ} \mathrm{C}\right)$ at the UAEM.

Coleomegilla maculata DeGeer (Coleoptera: Coccinellidae) is an important predator of the CPB in potato fields (Groden et al. 1990). It was important to note any possible attack by the Mexican $L$ subgrandis on this coccinellid. For this purpose, I set up two petri dishes, each containing four starved $L$ subgrandis. One dish received 110 and the other 124 C. maculata eggs placed on segments of potato leaves. In a second trial, I offered newly emerged larvae of $C$. maculata to $L$. subgrandis, placing 50 larvae per dish in two sets of dishes containing four starved carabids each. Consumption of $C$. maculata eggs was recorded after 72 hours, when most of the eggs started to hatch. I recorded the consumption of $C$. maculata larvae after 24 hours. I did not remove residues or add new food to the dishes during the trials, but added water to keep the dish moist.

In a second test, I provided six L. subgrandis with an excess of CPB eggs and larvae for three days. Then I took all intact CPB eggs or larvae and residues out of the dishes, and left the insects to starve for two to three hours. I then placed $102 C$. maculata eggs on segments of potato leaves in one dish with six carabids and recorded the insects' behavior for the next five hours. Later, I checked the dish 
regularly and kept moisture constant. After 24 hours, most of the $C$. maculata eggs hatched and I placed 50 of the new larvae on a clean dish; I offered the larvae to $L$. subgrandis and observed the insects' behavior for 5 hours. Daily consumption was recorded for four days. I did not remove residues or add new food to the dishes or offer any other type of prey to $L$. subgrandis during this time.

In a third experiment, I offered 26 eggs or 20 newly hatched nymphs of Oplomus sp. (Hemiptera: Pentatomidae) on segments of Solanum sp. leaves to one set of four starved adult $L$. subgrandis in separate trials lasting 2 days. Residues were not removed, and I did not add new food to the dish during the trial. I checked the eggs and nymphs for signs of carabid attack and recorded consumption. Water was added to keep the dish moist.

I also offered 10 second instar nymphs of a reduviid CPB predator (Hemiptera: Reduviidae) to one set of two starved female L. subgrandis. The trial lasted less than 48 hours due to mortality of the nymphs. New nymphs were not added during this time. I removed dead nymphs, recorded consumption, and checked the dead nymphs for signs of carabid attack. Water was added to keep the dish moist.

Finally, L. grandis Hentz did well on a diet of aphids (Homoptera: Aphidae) (Groden 1989). Because this species is related to L. subgrandis, I also offered aphids to five pairs of the mexican carabid. The aphids were taken from $S$. rostratum plants kept in the greenhouse at URI. I recorded the number of aphids consumed by the carabids, removed the residues, and added more aphids during two days. It was not possible to conduct the test under these conditions for a long time due limited numbers of aphids; however, I was able to observe whether $L$. 
subgrandis beetles would survive eating aphids which I offered for more than 2 months, when available.

Oviposition by $L$. subgrandis. L. subgrandis is univoltine in Morelos. In early rearing experiments (Aranda, unpublished data), I had difficulty getting the newly emerged femlaes to lay eggs. The purpose of the following experiments was to describe the seasonality of $L$ subgrandis fecundity. I categorized field collected $L$. subgrandis by season: Those collected in June-July 1990 were labeled "early summer." Those collected in August-September 1990 were labeled "late summer." I placed 25 females from each category in individual plastic petri dishes containing soil from the same sites where I collected the insects.

Seasonality of $L$. subgrandis fecundity, I. In this experiment, I tested the influence of season and mating status on fecundity. Individual fecundity was measured as the number of $L$. subgrandis first instar larvae produced per female. I used five mating categories, each using five females in individual dishes. The categories were: females confined with males for 1,2 , or 3 days, or for the entire experiment. A fifth group of females was never confined with males. I offered CPB eggs, 1st, 2nd, or 3rd instar larvae in excess, depending on what was available at that time. The females stayed on the soil for 6 days, after which I moved them to new dishes containing clean soil. The soil was changed nine times for the "early summer" females, and five times for the "late summer" females. After every change, I kept the "old" soil at room temperatures $\left(22-26^{\circ} \mathrm{C}\right)$ for 7 days of incubation. After 7 days, I emptied each petri dish and spread the contents on a paper towel. All active $L$. subgrandis first instar larvae were collected and counted. The soil was moistened after checking and returned to the shelf for further incubation. I checked the dishes 
daily for 8 days. An Analysis of Variance (PROC GLM, SAS Institute 1990) was used to estimate the influence of season and mating status on the production of first instar larvae by female $L$. subgrandis.

Seasonality of $L$. subgrandis fecundity, II. This experiment was designed to test recently emerged female $L$. subgrandis for fecundity. I confined two female $L$. subgrandis, caught in the emergence cages, with males ( 1 female and 2 males per dish). I kept three more isolated from the time they were captured in the emergence cages. The insects were placed in plastic petri dishes containing a $2 \mathrm{~mm}$ layer of Mexican soil. I offered CPB eggs, 1st, 2nd, or 3rd instar larvae in excess, depending on what was available at that time. The insects stayed on the soil for 6 days and then I moved them to new dishes containing clean soil. The soil was changed five times for females confined with males and four times for the ones that were never mated. I processed the soil following the same steps described above.

Survival of $L$. subgrandis first instar larvae. I used the larvae obtained in the fecundity experiments to estimate 1st instar longevity. Larvae were kept in plastic petri dishes lined with moistened paper towel. Twenty dishes were set up with a density of larvae that varied from day to day, from a minimum of 18 to a maximum of 246 . I kept the dishes at room temperature $\left(22-26^{\circ} \mathrm{C}\right)$ and recorded the number still alive daily until all died.

Development of ovaries in L. subgrandis. I took samples of three to five females at intervals of 3 to 10 days, from July 3rd through August 13th 1990. The insects were killed in $70 \%$ ethyl alcohol and immediately dissected. Other females that died on the way to the lab were preserved in $70 \%$ ethyl alcohol and immediately dissected. In every female, I checked the state of the ovarian follicles 
and recorded if they were developed, undeveloped, or regressed. I also recorded coloration, number of eggs contained in the egg chambers, and when possible, the state of the oviducts to see whether the eggs were ready to be laid.

Overwintering of adult $L$. subgrandis. To assess the adaptability of $L$. subgrandis to winter conditions, I placed 10 males and 30 females in a growth chamber set at $21^{\circ} \mathrm{C}$ and a photoperiod of $\mathrm{L}: \mathrm{D}=16: 8$. The experiment started in October 1990. I kept the insects at $21^{\circ} \mathrm{C}$ for about 2 weeks and always with food (CPB eggs, 1st, 2nd, or 3rd instar larvae depending on what was available at that time). After 2 weeks, I reduced the temperature by $3^{\circ} \mathrm{C}$ every 4 days until it reached $10^{\circ} \mathrm{C}$. At and above $10^{\circ} \mathrm{C}, L$. subgrandis was offered CPB eggs or larvae in excess. L. subgrandis stopped eating at $13^{\circ} \mathrm{C}$. The carabids were kept 5 days at $10^{\circ} \mathrm{C}, 6$ days at $7^{\circ} \mathrm{C}, 30$ days at $5^{\circ} \mathrm{C}$, and 40 days at $0^{\circ} \mathrm{C}$. I did not offer any CPB prey below $10^{\circ} \mathrm{C}$. After completing the 40 -day period at $0^{\circ} \mathrm{C}$, I brought the temperature up to $25^{\circ} \mathrm{C}$, by increases of $4^{\circ} \mathrm{C}$ every 3 days. However, the experiment ended at $16^{\circ} \mathrm{C}$, when I found all the insects were dead.

Survival of field-collected $L$. subgrandis. The longevity of field-collected $L$. subgrandis was estimated for seven females and nine males. Six females and seven males were collected July 19, 1990. Two males were obtained from emergence cages on August 6 and a female on August 13, 1990. I set up the insects in plastic petri dishes lined with moistened paper towel. The insects were confined the day they were captured. I assumed the insects captured in the emergence cages were newly emerged adults (new generation for 1990) or recently emerged hibernating adults (from the 1989 generation). The food consisted of CPB eggs and larvae. The insects were kept at room temperatures $\left(22-26^{\circ} \mathrm{C}\right)$ in Morelos. I continued the 
study in Rhode Island with the same insects kept in a growth chamber at $25^{\circ} \mathrm{C}$. I cleaned the dishes regularly and offered food daily. The survival time recorded was the numbers of days the insects stayed alive from the set up of the dishes until the date they died naturally. 


\section{RESULTS}

Field Investigations

From the incidence data (Fig. 1) I conclude that there are two emergence periods for $L$. subgrandis, in early July and mid-August. Hibernating $L$. subgrandis adults may emerge in late June to early July. Although not proven experimentally, soil moisture, due to rainfall, may play an important role in emergence of $L$. subgrandis, as it does with most insects in the region. Starting in June 1990, I was looking for areas with CPB and noticed that field populations were building up by June 27th; in two early samples (before the sites were chosen), I found 0.9 adult CPB/plant (19 plants) and 1.5 adult CPB/plant (13 plants). No adults of $L$. subgrandis were observed then. Later, I recorded the first incidence of $L$. subgrandis on July 3 rd in the plot at the Chiverias site (42 carabids), and a peak incidence three days later (58 carabids). A second peak occurred August 10th in the plot at the Tequesquitengo site (40 carabids). The peak incidence in August suggests a generation of new adults, considering that development from first instar to adult takes 25 to 28 days at $25-26^{\circ} \mathrm{C}$. Although higher temperatures in the sites might shorten the development time of this species, the availability of food may play an important role in the size of the August generation of L. subgrandis. Females of the August generation ("late summer" females) laid fewer eggs (see below: section Oviposition by L. subgrandis).

The similarity of the incidence curves between adult CPB's and adult $L$. subgrandis is noteworthy (Fig. 1): the numbers of $L$. subgrandis predators are positively correlated with the numbers of adult $\mathrm{CPB}\left(\mathrm{Y}=-1.76+0.84 \mathrm{X} ; \mathrm{R}^{2}=0.337\right.$, $\mathrm{p}=0.005$ ). Apparently, the carabid is dependent on its prey. When adult CPB 
Figure 1. Number of adult CPB's per plant (-..--) and adult Lebia subgrandis per plant (—), Chiverias site (7/3/90 to 8/17/90) and Tequesquitengo site (8/20/91 to $9 / 21 / 91)$, Morelos, Mexico. 


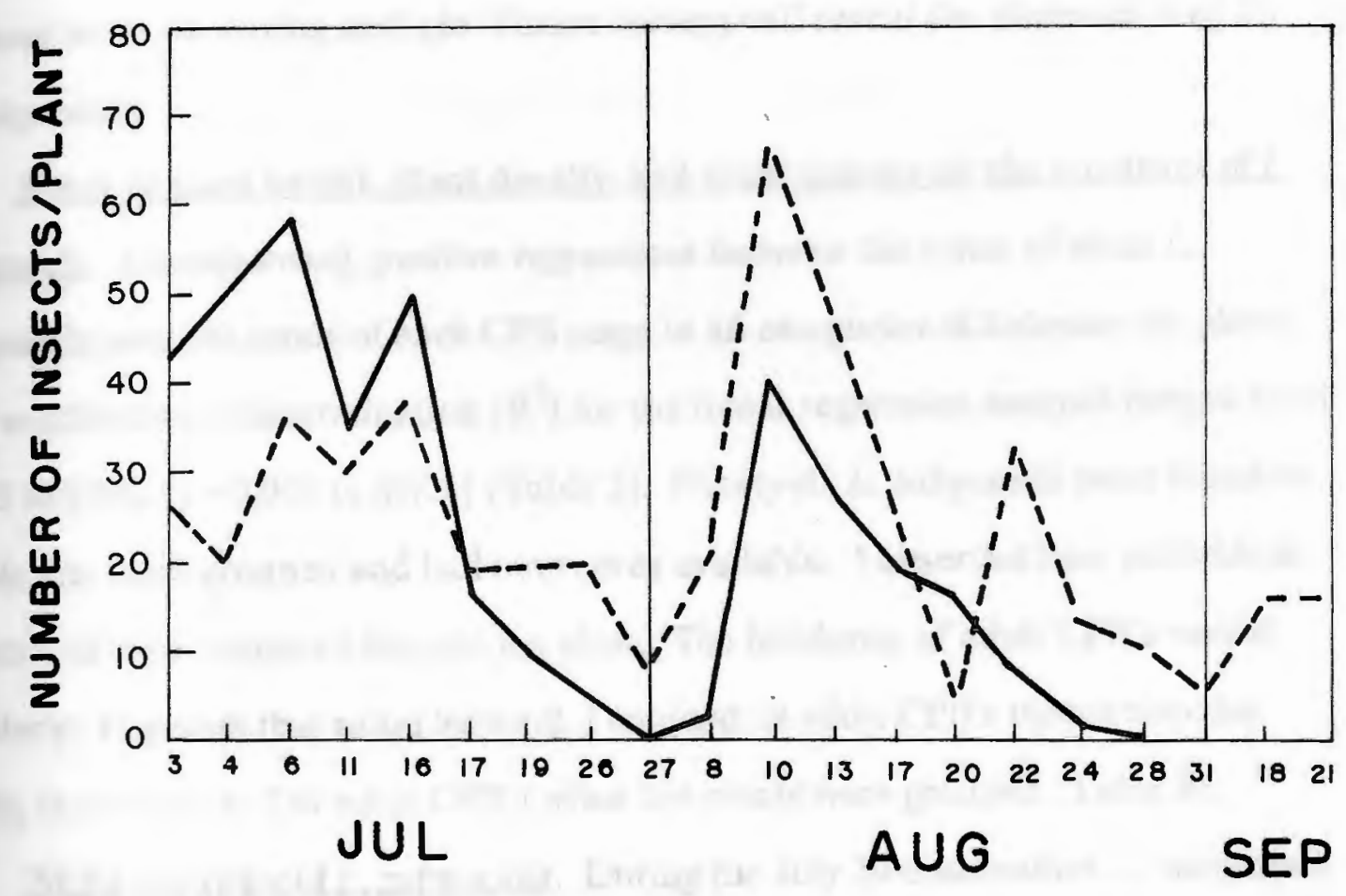


densities were very low, I observed no adult carabids within the plots (Fig. 1).

L. subgrandis, however, may depend upon an alternate prey for survival: I recorded 24 individuals in the weeds around the plot on July 19, four on July 27, 20 on August 6, and 17 on September 18, when the density of adult CPB's was between 0.8 and 2.0 per plant. Even when host plants were nearly defoliated and carrying few CPB prey, as on the night of July 29 th, I recorded 28 active $L$. subgrandis within the area but none during daylight. Future surveys will reveal the alternate prey for L. subgrandis.

Effect of plant height, plant density, and foliar density on the incidence of $L$. subgrandis. I found strong, positive regressions between the totals of adult $L$. subgrandis over the totals of each CPB stage in all categories of Solanum sp. plants. The coefficients of determination $\left(R^{2}\right)$ for the linear regression analysis ranged from 0.703 to 0.982 ( $\mathrm{p}=0.001$ to 0.018 ) (Table 2). Ninety-six L. subgrandis were found on plants that were grouped and had more prey available. I observed four carabids in plants that were scattered beyond the plots. The incidence of adult CPB's varied similarly: In plants that stood isolated, I counted 28 adult CPB's throughout the study, in contrast to 554 adult CPB's when the plants were grouped (Table 3).

Nightly activity of L. subgrandis. During the July 29 observation, $L$. subgrandis was less active at dusk, but its numbers increased before midnight. The numbers of carabids decreased sharply after midnight, apparently due to light rainfall (Fig. 2). Once the rain ceased, I observed as many as eight individuals within my plot from 4 to 6 a.m. During the early morning (6 a.m.) the number of carabids decreased again (perhaps due to the dew on the plants). By mid-morning (9-10 a.m.) the number of $L$. subgrandis increased again. On the second night of observations, 
Table 2. Coefficients of determination $\left(R^{2}\right)$ and equations for linear regressions between totals of Lebia subgrandis (Y) and CPB life stages (X).

CPB Stage

Adult

Eggs

1st Instar

2nd Instar

3rd Instar

4th Instar
Equation

$$
Y=2.8+0.167 X
$$$$
Y=-12.3+0.939 X
$$$$
Y=4.0+0.338 X
$$$$
Y=-3.5+0.629 X
$$$$
Y=-9.1+0.546 \mathrm{X}
$$$$
\mathrm{Y}=0.52+0.354 \mathrm{X}
$$$$
0.703
$$

0.963
$\mathrm{F}(1.5)^{1}$

272.25 *

$65.81 *$

$32.41 *$ 25.35 * $11.86^{*}$ 131.50 *

$1^{*}=$ Significant at $\mathrm{p}<0.05$ 
Table 3. Effect of plant height, density, and foliar density on CPB egg, larval and adult and Lebia subgrandis adult incidence (number per plant), July 11 to August 24, 1990. (MEAN \pm s.d., $N=11$ plants)

\begin{tabular}{lllllll} 
L. subgrandis & \multicolumn{5}{c}{ Colorado potato beetle stage } \\
Adults & Eggs & $\underline{L}_{1}$ & $\underline{L}_{2}$ & $\underline{L}_{3}$ & $\underline{L}_{4}$ & $\underline{\text { Adults }}$
\end{tabular} Plant Height

Tall $\quad 1.4 \pm 1.7 \quad 2.1 \pm 2.6 \quad 0.0 \pm 0.0 \quad 0.5 \pm 1.2 \quad 3.0 \pm 4.2 \quad 5.5 \pm 6.0 \quad 9.8 \pm 6.4$

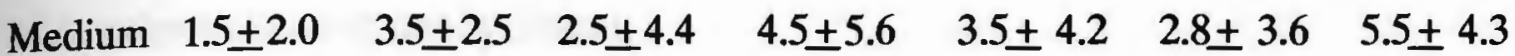

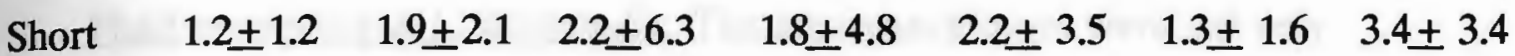

\section{Plant Density}

High $\quad 8.7 \pm 10.3 \quad 10.1 \pm 7.8 \quad 22.3 \pm 28.4 \quad 12.7 \pm 15.914 .5 \pm 14.5 \quad 23.8 \pm 24.250 .4 \pm 23.8$

Low $\quad 0.4 \pm 0.7 \quad 2.7 \pm 3.2 \quad 0.1 \pm 0.3 \quad 2.3 \pm 5.5 \quad 7.4 \pm 19.1 \quad 0.5 \pm 0.8 \quad 2.5 \pm 3.2$

\section{Foliar Density}

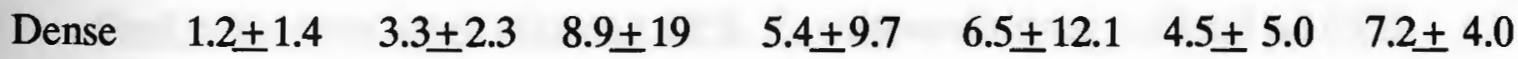

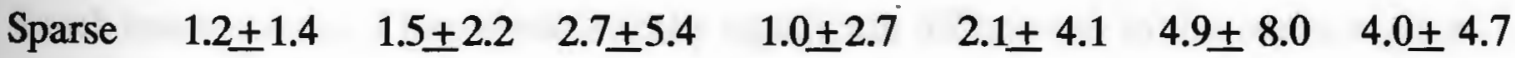


August 26, heavy rain suppressed the activity of $L$. subgrandis all night long. However, I observed three individuals at dusk and two more from 6 to 8 a.m.. Additionally, these insects were not active during the hottest hours of the day in open fields (i.e., 11:30 a.m. to 3:00 p.m.). I found them to be active especially in shaded areas where Solanum sp. carried CPB. In some surveyed sites, in spite of an abundance of Solanum sp. plants with plentiful CPB eggs and larvae on them, adults of $L$. subgrandis were totally absent.

Field emergence of $L$. subgrandis. The emergence cages were not very successful. I had to move the cages three times during the study because they disappeared (stolen) or because they were producing no insects. Nine L. subgrandis emerged in the cages: seven females and two males, which I used for oviposition and survival experiments. It was not possible to draw conclusions for emergence of L. subgrandis with this data.

\section{Laboratory Experiments}

Food preference using Mexican CPB. L. subgrandis does not feed on CPB fourth instar larvae. I found statistically significant differences in the consumption rates by sex grouping $(F[2,468]=34.0, p<.05)$, and stage of $C P B$ offered $(F[3,468]=$ $493.4, \mathrm{p}<.05$ ). I also found significant interaction between sex grouping and stage of $\mathrm{CPB}$ offered $(\mathrm{F}[6,468]=18.5, \mathrm{p}<.05)$. Given the significant interaction, it was interesting to note differences in consumption of CPB stages by $L$. subgrandis in three sex groupings: A simple effects test (Keppel 1982) by sex grouping showed statistically significant differences in consumption of CPB eggs among females, males, and pairs $(F[2,468]=86.37, p<.05)$. The consumption rate of eggs by pairs of L. subgrandis was significantly different from the combined consumption rates by 
Figure 2. Number of adult Lebia subgrandis recorded at night at the Chiverias site (7/29/91 and 8/26/91). All active adults were recorded visually over a $30 \mathrm{~min}$. observation period every 2 hours. 


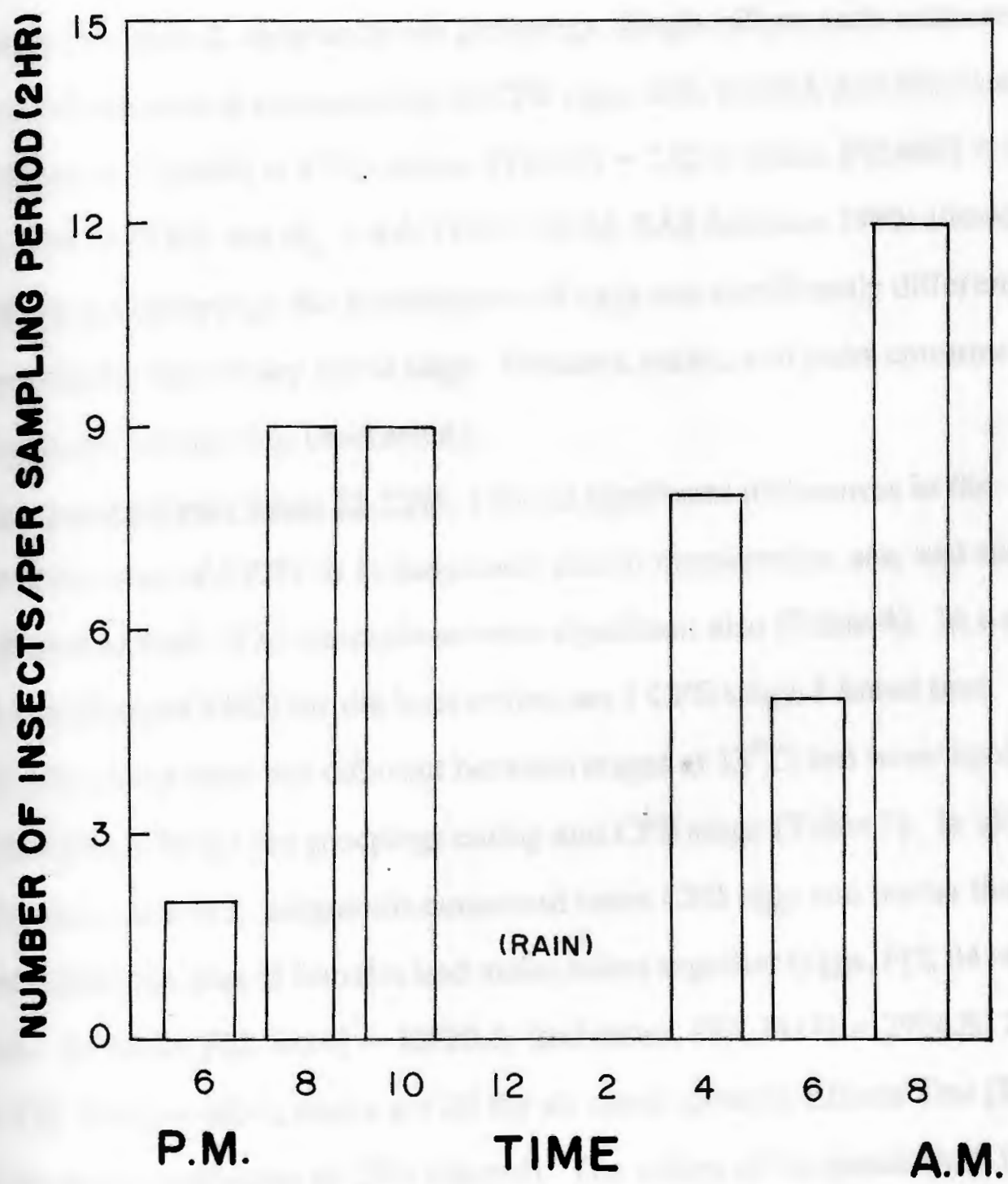


females and males together (TUKEY test, $d_{t}=3.7$, PROC GLM, SAS Institute 1990), but there were no significant differences in the consumption rate of first, second, or third instar CPB's attributable to the three sex groupings.

Within the three $L$. subgrandis sex groupings, simple effects tests indicated significant differences in consumption of CPB eggs, first, second, and third instar larvae (females, $F[3,468]=87.9$; males, $F[3,468]=133.4$; pairs, $F[3,468]=311.1$, $p<.05)$. The TUKEY test $\left(d_{t}=4.0\right.$, PROC GLM, SAS Institute 1990) showed that for all three sex groupings, the consumption of eggs was significantly different from the consumption rate of any larval stage. Females, males, and pairs consumed very few third instar larvae (See Discussion).

Consumption rate using RI CPB. I found significant differences in the consumption rates of CPB's by $L$. subgrandis due to temperature, sex, and stage of CPB offered as food. The interactions were significant also (Table 4). In a simple effects test (Keppel 1982) for the interaction, sex / CPB stage, I found that consumption rates were not different between stages at $13^{\circ} \mathrm{C}$, but were significant at $16^{\circ} \mathrm{C}$ and above for all sex groupings eating and CPB stage (Table 5). In all the experiments, pairs of $L$. subgrandis consumed more CPB eggs and larvae than expected from the sum of females and males taken together (eggs, $\mathrm{F}[2,3414]=$ 10434.6; 1st instar, $F[2,3414]=18529.8 ; 2$ nd instar, $F[2,3414]=2954.8 ; 3 r d$ instar $F[2,3414]=603.1$, where $p<.05$ for all cases) (Simple Effects Test [Keppel 1982] for sex at each stage of CPB offered). The values of the parameters in the linear model are shown in Table 6. For the experimental conditions used here, the predicted values for consumption fit a linear trend showing strong regressions between the interaction, sex / CPB stage, and temperature (Figs. 3, 4, 5). There was 
Table 4. Three-way ANOVA summary for consumption of RI CPB by Lebia subgrandis.

\begin{tabular}{|c|c|c|c|c|}
\hline Source & df & Sum of Squares & Mean Square & $\underline{\text { FRatio }}^{1}$ \\
\hline Sex (Group) & 2 & 40261.4 & 20130.7 & $464.3^{*}$ \\
\hline Temperature & 1 & 44169.5 & 44169.5 & $1018.7^{*}$ \\
\hline Food (Stage) & 3 & 83401.2 & 27800.4 & $641.2^{*}$ \\
\hline Temp * Sex & 2 & 31110.8 & 15555.4 & $358.8^{*}$ \\
\hline Sex * Food & 6 & 14311.1 & 2385.1 & $55.0^{*}$ \\
\hline Temp $*$ Food & 3 & 13588.7 & 4529.6 & $104.5^{*}$ \\
\hline Temp ${ }^{*}$ Sex ${ }^{*}$ Food & 9 & 11948.0 & 1327.6 & $45.9^{*}$ \\
\hline Error & 3414 & 148029.3 & 43.4 & \\
\hline Total & 3437 & 386819.8 & & \\
\hline
\end{tabular}


one exception (Fig. 4a) where I observed no relation at all.

The mean consumption rate of CPB stages by $L$. subgrandis increased at warm temperatures $\left(16\right.$ to $28^{\circ} \mathrm{C}$ ), but it was low when temperature dropped to $13^{\circ} \mathrm{C}$ (Table 7). It is doubtful that $L$. subgrandis will consume any stage of CPB at temperatures below $13^{\circ} \mathrm{C}$. It is also possible that differences in metabolism and reproductive physiology between female and male L. subgrandis may influence the consumption rate.

Host specificity of adult $L$. subgrandis. When offered $C$. maculata eggs, starved $L$. subgrandis approached the food immediately, just as they do when offered $\mathrm{CPB}$ eggs or larvae. Some tried to bite the eggs, then retreated. Others bit the surface of the leaf just around the base of the eggs. This kind of behavior was common initially, though later the beetles settled down and seldom approached the eggs. I recorded no consumption of eggs. Although some of them showed signs of having been "tasted," the chorion was intact. Also, no C. maculata larvae were consumed, and most died naturally with no signs of carabid attack.

When I used non-starved $L$. subgrandis, as soon as I placed $C$. maculata eggs into the petri dish, the beetles approached the eggs, as if they were not satiated by the previous abundant feeding. Then, they suddenly stopped as if they were "tasting" the area around the eggs. They "bit" (or at least that was the motion they were performing) the leaf surface, touched the eggs, and left without eating. $L$. subgrandis did not eat $C$. maculata larvae. The carabid did not even approach them. By the end of the trial, almost all of the larvae were dead, yet none had been eaten.

When I offered pentatomid eggs or nymphs, the beetles did not even approach them; neither eggs nor nymphs were eaten. If offered reduviid nymphs as food, the 
Figure 3. Observed (— $\longrightarrow$ ) and predicted (- . - -) daily consumption of CPB prey by female Lebia subgrandis. 

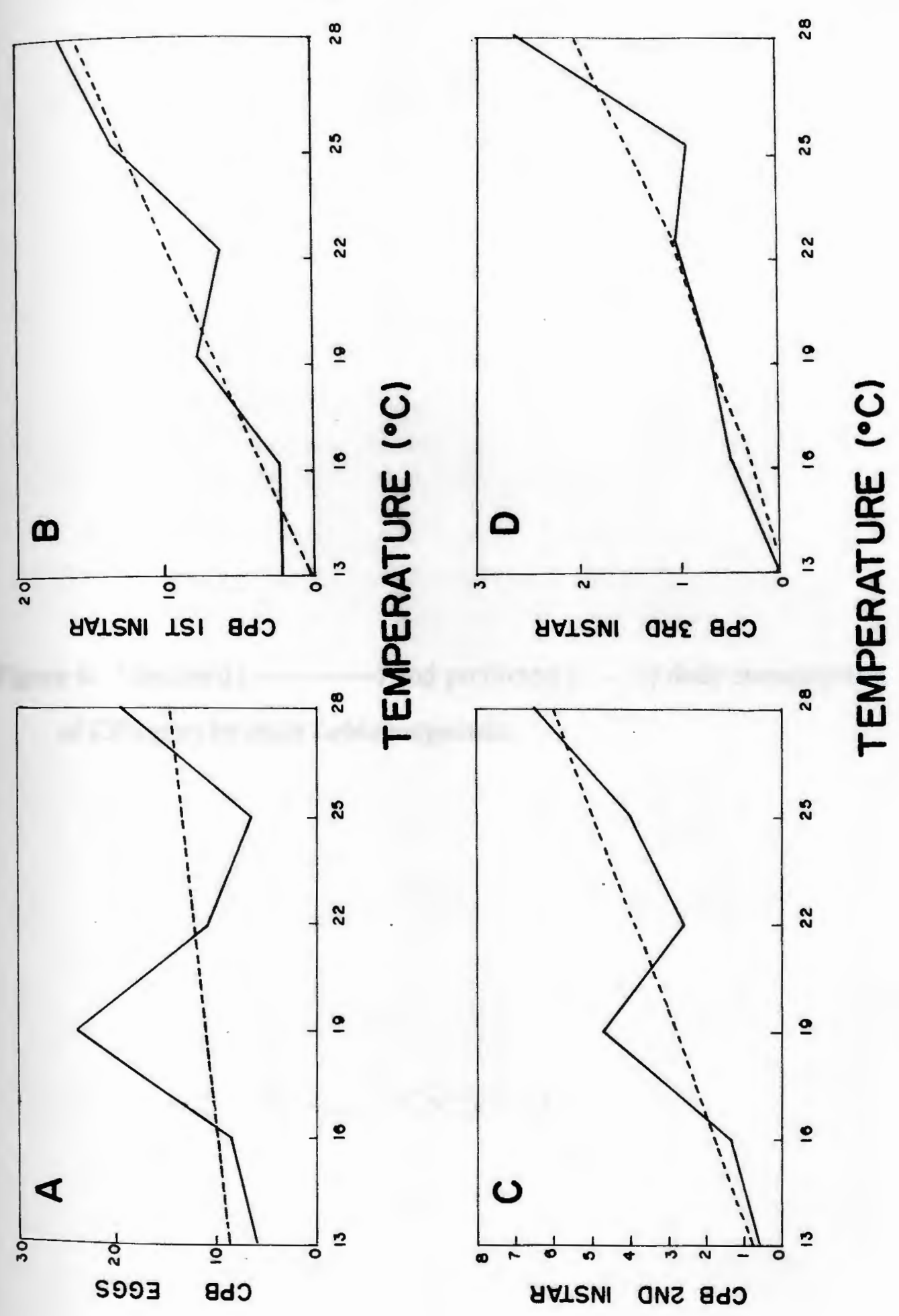

29 
Figure 4. Observed (— $\longrightarrow$ and predicted (- - - - ) daily consumption of CPB prey by male Lebia subgrandis. 

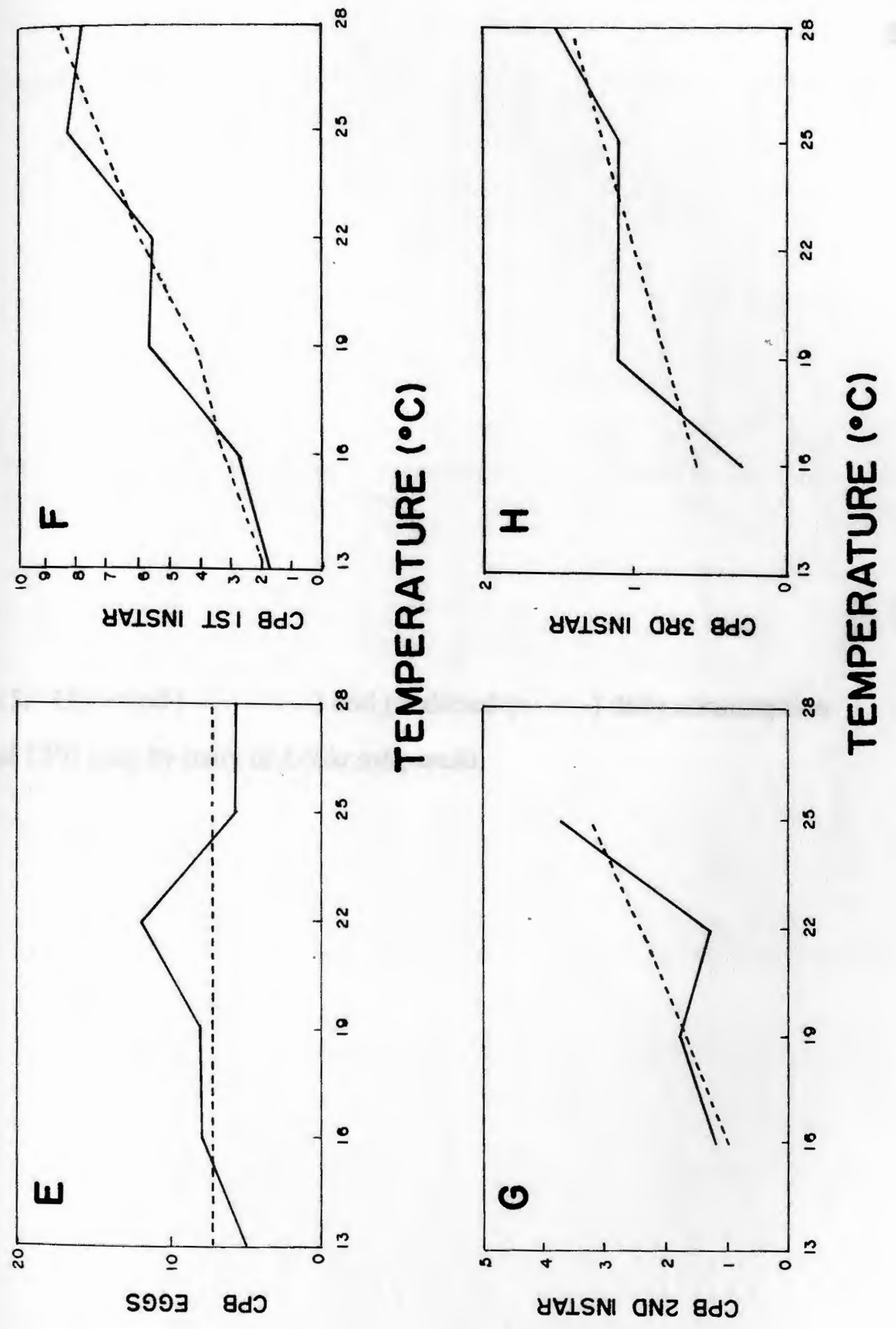
Figure 5. Observed (_- ) and predicted (- - - - ) daily consumption of CPB prey by pairs of Lebia subgrandis. 

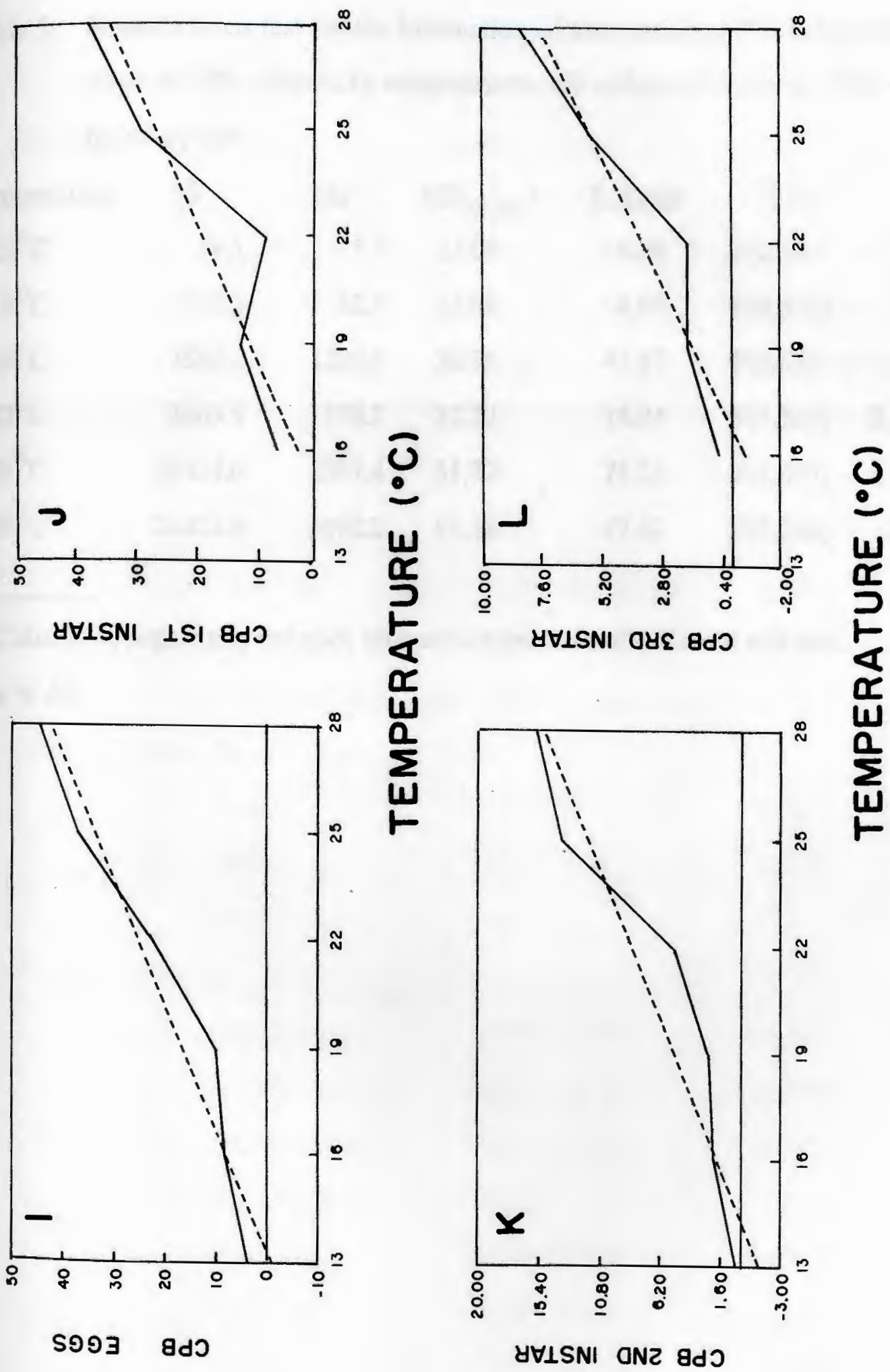
Table 5. Simple effects test for the interaction of sex grouping of $L$. subgrandis and stage of CPB offered, by temperature. SS = Sum of squares. MS = Mean square.

\begin{tabular}{lrrrrr} 
Temperature & \multicolumn{1}{l}{ SS } & \multicolumn{1}{c}{ MS } & $\underline{\text { MS }}_{\text {error }}{ }^{1}$ & F Ratio & $\underline{\text { F Tab }}^{2}$ \\
\cline { 1 - 5 } $13^{\circ} \mathrm{C}$ & 34.1 & 5.7 & 12.05 & 0.46 & $\mathrm{~F}(2,386)=3.00$ \\
$16^{\circ} \mathrm{C}$ & 376.3 & 62.7 & 15.68 & 4.00 & $\mathrm{~F}(6,579)=2.10$ \\
$19^{\circ} \mathrm{C}$ & 7683.1 & 1280.5 & 30.95 & 41.37 & $\mathrm{~F}(6,633)=2.10$ \\
$22^{\circ} \mathrm{C}$ & 2869.5 & 478.2 & 32.22 & 14.84 & $\mathrm{~F}(5,560)=2.21$ \\
$25^{\circ} \mathrm{C}$ & 14324.6 & 2387.4 & 31.72 & 75.26 & $\mathrm{~F}(6,667)=2.10$ \\
$28^{\circ} \mathrm{C}$ & 23352.9 & 3892.2 & 81.39 & 47.82 & $\mathrm{~F}(5,548)=2.21$
\end{tabular}

1 Calculated separately for each interaction because of different cell size.

$2 \mathrm{p}<.05$ 
Table 6. Coefficients of the general linear model for the consumption of CPB prey by $L$. subgrandis (female, male, and pairs).

Parameter

Intercept

Sex Grouping Female

Male

Pairs

Temperature

CPB Stage

$$
\begin{aligned}
& \text { Egg } \\
& \text { 1st Instar } \\
& \text { 2nd Instar } \\
& \text { 3rd Instar }
\end{aligned}
$$

Temperature by Sex

Female
Male
pairs

Sex by CPB Stage

$\begin{array}{lrll}\text { Female/Egg } & 31.94 & (3.73) & 0.0001 \\ \text { Female/1st } & 15.25 & (3.95) & 0.0001 \\ \text { Female/2nd } & 2.72 & (3.70) & 0.4629 \\ \text { Female/3rd } & 0.00 & & \\ \text { Male/Egg } & 34.26 & (4.10) & 0.0001 \\ \text { Male/1st } & 22.67 & (4.33) & 0.0001 \\ \text { Male/2nd } & 2.30 & (4.67) & 0.6220\end{array}$

Estimate (s.e.)

-10.90 (2.19)

8.99 (3.04)

$10.29 \quad(3.48)$

0.00

$0.65 \quad(0.09)$

$-26.48 \quad(2.68)$

$-25.80 \quad(2.99)$

$-4.60(2.65)$

0.00
$-0.52(0.13)$

0.0001

$\begin{array}{lll}-0.58 & (0.14) \quad 0.0001\end{array}$

0.00
0.0001

0.0001

0.0001

0.0827

$P>|\mathrm{T}|_{0.10}$

0.0001

0.0032

0.0032$$
0.0827
$$ 
Table 6. (continued)

Sex by CPB Stage

$\begin{array}{ll}\text { Male/3rd } & 0.00 \\ \text { Pairs/Eggs } & 0.00 \\ \text { Pairs/1st } & 0.00 \\ \text { Pairs/2nd } & 0.00 \\ \text { Pairs/3rd } & 0.00\end{array}$

Temperature by CPB Stage

$\begin{array}{llll}\text { Egg } & 2.17 & (0.12) & 0.0001 \\ \text { 1st Instar } & 1.87 & (0.13) & 0.0001 \\ \text { 2nd Instar } & 0.43 & (0.11) & 0.0003 \\ \text { 3rd Instar } & 0.00 & & \end{array}$

Temperature, Sex, Stage

$\begin{array}{llll}\text { Female/Egg } & -1.91 & (0.17) & 0.0001 \\ \text { Female/1st } & -1.00 & (0.17) & 0.0001 \\ \text { Female/2nd } & -0.21 & (0.16) & 0.1904 \\ \text { Female/3rd } & 0.00 & & \\ \text { Male/Egg } & -2.24 & (0.18) & 0.0001 \\ \text { Male/1st } & -1.50 & (0.19) & 0.0001 \\ \text { Male/2nd } & -0.26(0.20) & 0.2113 \\ \text { Male/3rd } & 0.00 & \\ \text { Pairs/Egg } & 0.00 & \\ \text { Pairs/1st } & 0.00 & \\ \text { Pairs/2nd } & 0.00 & \\ \text { Pairs/3rd } & 0.00 & \end{array}$


Table 7. Daily consumption (Mean +s.d.) of CPB's by Lebia subgrandis, by temperature.

Temperature $\left({ }^{\circ} \mathrm{C}\right)$

13

16

19

22

25

\section{CPB Stage}

Egg

1st Instar

2nd Instar

Egg

1st Instar

2nd Instar

3rd Instar

Egg

1st Instar

2nd Instar

3rd Instar

Egg

1st Instar

2nd Instar

3rd Instar

Egg

1st Instar

2nd Instar

3rd Instar
Females

$5.9 \pm 5.6$

$2.2+2.4$

$0.6 \pm 0.9$

$8.6 \pm 7.8$

$2.4 \pm 2.3$

$1.4 \pm 1.2$

$0.5 \pm 0.7$

$24.0 \pm 9.0$

$7.7 \pm 3.8$

$4.7 \pm 3.0$

$0.7 \pm 0.8$

$10.7 \pm 6.8$

$6.2 \pm 3.9$

$2.6 \pm 1.9$

$1.0 \pm 0.7$

$6.5 \pm 7.3$

$13.4 \pm 5.9$

$4.1 \pm 2.8$

$0.9 \pm 0.7$
Males

Pairs

$5.0 \pm 4.63 .8+4.8$

$1.8 \pm 1.5$

$0.5 \pm 0.8$

$7.9 \pm 5.6 \quad 8.3 \pm 7.4$

$2.8 \pm 1.8 \quad 7.1 \pm 4.5$

$1.2 \pm 0.8 \quad 2.2 \pm 1.2$

$0.3 \pm 0.5$

$0.6 \pm 0.6$

$8.1 \pm 7.010 .2 \pm 9.6$

$5.7 \pm 3.413 .0 \pm 7.0$

$1.8 \pm 1.3 \quad 2.7 \pm 1.9$

$1.1 \pm 0.9 \quad 1.8 \pm 1.5$

$11.9 \pm 8.3 \quad 22.4 \pm 13.8$

$5.6 \pm 3.8$

$8.7 \pm 5.0$

$1.3 \pm 1.15 .2 \pm 2.9$

$1.8 \pm 1.3$

$5.7 \pm 5.2 \quad 36.9 \pm 14.0$

$8.3 \pm 4.8 \quad 29.0 \pm 6.6$

$3.7 \pm 2.6 \quad 13.8 \pm 5.4$

$1.1 \pm 0.8 \quad 5.6 \pm 1.7$ 
Table 7. (continued)

$\begin{array}{cllcc}\text { Temperature }\left(^{\circ} \mathrm{C}\right) & \text { CPB Stage } & \text { Females } & \text { Males } & \text { Pairs } \\ 28 & \text { Egg } & 19.7 \pm 10.6 & 5.6 \pm 6.6 & 44.5 \pm 21.3 \\ & \text { 1st Instar } & 16.9 \pm 7.9 & 7.8 \pm 3.7 & 37.8 \pm 14.8 \\ & \text { 2nd Instar } & 6.5 \pm 2.8 & & 15.7 \pm 7.1 \\ & \text { 3rd Instar } & 2.6 \pm 1.6 & 1.5 \pm 1.3 & 8.3 \pm 5.2\end{array}$


carabids did not consume any. Later, all nymphs died, but I never observed any being attacked by $L$. subgrandis.

L. subgrandis ate aphids. The mean consumption by six non-starved pairs was 24.2 aphids/pair (range 5 to 40, s.d. = 10.2). The carabids survived from October 16 until December 21, 1990 with an irregular diet of aphids. Two $L$. subgrandis beetles died during the trial, one male in October 23, and a female in December 9. I stopped the experiment because the potato and $S$. rostratum plants in the greenhouse had been sprayed to kill the aphid populations.

Oviposition by Lebia subgrandis.

Seasonality of $L$. subgrandis fecundity, I. I found a strong significant difference in the oviposition rate between "early summer" and "late summer" $L$. subgrandis $(\mathrm{F}[1,40]=10.46, \mathrm{p}<.05)$; the rate difference due to mating status was moderate $(F[4,40]=3.23, p<.05)$. It seems that mating need not be frequent to assure fertilization. "Early summer" females laid more eggs than those collected by the end of summer, possibly because a considerable number of "late summer" females were newly emerged. The interaction was not significant $(F[4,40]=0.63$, $p<.05)$. The TUKEY test for mating status $\left(d_{t}=4.03\right)$ showed that the number of first instar larvae produced by females confined 1 or 2 days with males was significantly different from the other conditions. However, the TUKEY test detected no difference between the conditions of 2 days or 1 day confinement with males.

Seasonality of $L$. subgrandis fecundity, II. Females obtained from the emergence cages (never confined with males) produced a mean of 44.8 first instar larvae; females also from emergence cages (never confined with males, produced 
12.7 first instar larvae. It is possible that most of the females that emerged in the cages were overwintering individuals that mated before the onset of the dry season.

Survival of $L$. subgrandis first instar larvae. I found that the first instar larvae of this carabid lived an average of $8.3 \pm 2.5$ days (range 6 to 13 days) at room temperature $\left(22\right.$ to $\left.26^{\circ} \mathrm{C}\right)$.

Development of ovaries in L. subgrandis. I dissected 57 females in July, 1990. Of 38 females from early July, 22 had eggs completely developed, and these eggs filled most of the insects' abdomens. The mean number of eggs was 34.3 (range 20 to 49 , s.d. $=8.5$ ). Two of the females had two and three eggs respectively left in the ovarioles, which looked shrunken. Seven of the females were immature (no eggs get developed), and six were mature (eggs developing). One female had eggs completely developed, but these were difficult to count because most of them were destroyed (with no apparent cause) and it was not possible to single them out.

By mid-July, of 17 females dissected, I recorded six females with eggs completely developed, with a mean of 54.0 eggs each (range 41 to 74 , s.d. $=13.6$ ). Eleven females were immature. Of two females dissected in late July, in one female the eggs had started to develop, while one other was still immature.

Of six females dissected in mid-August, I observed that they had ovarioles which I considered "regressed." These ovarioles looked extremely loosened and were pale-brown or grayish in coloration. I assumed that these were females that had laid eggs recently.

The dissection of females was continued in Rhode Island with females collected in Mexico during the summer of 1990. In mid-October, I found that 12 females collected by the end of the summer had the ovarioles "regressed", while in 
early November one female had the ovarioles still active, showing eggs at different stages of maturation: Its end chambers were filled with 23 developed eggs. However, no eggs were found on the lateral oviducts or on the common oviduct. That is, there was no evidence that eggs were going to be laid soon. In mid-November, one "early summer" female had ovarioles that were very thin (thread-like) and difficult to distinguish from each other. However, the end parts of these egg chambers showed an amber coloration and tiny dark-brown marks at their very tip. It is at this time perhaps that "early summer" females become reproductively inactive, with no production of oocytes, which is why the ovarioles looked very thin. One female collected in the late summer had the ovarioles still active, with eggs at different stages of maturation, and the end of the chambers filled with 23 developed eggs. No eggs were observed in the lateral oviducts or on the common oviduct. In late November, the ovarioles of the females collected in the early summer were empty, shrunken, and with pale-yellowish coloration. In mid-December, five females from the late summer had the ovarioles "regressed."

Overwintering of adult $L$. subgrandis. All female and male $L$. subgrandis died by Februrary 15, 1991. I observed that some individuals may resist temperatures as low as $10^{\circ} \mathrm{C}$, where they could still move but had almost no feeding.

Survival of field-collected adult $L$. subgrandis. The mean survival time for seven female $L$. subgrandis was 78.0 days (range 35 to 111 , s.d. $=32.0$ ); for nine males the mean survival time was 79.4 days (range 45 to 129 , s.d. $=35.3$ ). A female caught in one of the emergence cages lived 87 days, and two males from the cages lived for 42 and 57 days, respectively. 
Miscellaneous observations. L. subgrandis may be confined in small groups under laboratory conditions. In the field, I have observed small gatherings of two or three insects sharing a hiding place. Sometimes, however, the crowding of the insects in containers may stimulate a defensive behavior. In this behavior, one of the beetles expels a pungent ammonia-like liquid (which immediately turns to gas), which can kill the other beetles in the container in several seconds. I do not know exactly what the conditions are for $L$. subgrandis to trigger this behavior, but one beetle can provoke a reaction by all of the other insects in the container, each expelling their own gases. In response, the insects appear to be agitated: they lift the elytra and vibrate the hind wings (although they do not attempt to fly), and run around the container with the elytra lifted. In one of my observations, one of the females expelled the gas, lifted the elytra, and appeared to be very agitated. When it faced the other three females in the container, although I expected a quick responce, there was none. If the container was not ventilated or the insects removed promptly, they would die in 30 to 60 seconds.

In spite of this defensive mechanism, sometimes I could see small gatherings of two or three insects sharing a hiding place. Also, under laboratory conditions, adults of $L$. subgrandis were observed to share prey (especially large thrid instar CPB larvae) without displaying any threatening behavior. Possibly this species does not exhibit strong territoriality, which is advantageous if several individuals have to search the same host plant for prey. 


\section{DISCUSSION}

L. subgrandis depends largely on the immature stages of the CPB to complete its own development. Accordingly, synchrony with its prey appears to be an important characteristic. L. subgrandis can, to a certain extent, synchronize its emergence with the numbers of CPB present in the same area. L. grandis populations are well syncronyzed with the CPB in both Rhode Island and Michigan (Groden 1989). In Morelos, adults of $L$. subgrandis start to appear later in the season (early July) when adult $L$. decemlineata (which appear by early to mid-June) are abundant enough to produce sufficient eggs or larvae to sustain the carabid.

The dependency of $L$. subgrandis on CPB stages for food was so striking that when populations of the CPB became very low, the carabids were totally absent. I think that when this occurs, adult carabids will crawl or fly towards surrounding weeds to look for alternative prey during the day and night, until the numbers of CPB increase again. Generally, whenever CPB's became sparse in the field plots, I found most of the adult carabids in the weeds surrounding the plots, and none within the plots. There must also be an alternative prey available at nights, but I have not been able to determine any likely hosts.

The numbers of adult $L$. subgrandis fluctuated over time, but remained correlated with the density of CPB's regardless of plant size, foliar density, or plant density. As seen from the data, L. subgrandis prefers grouped plants which offer more places for hiding and attract more CPB's. On the other hand, isolated plants are more exposed to a wide array of other predators (including those that prey on $L$. subgrandis plus others that prey on CPB); this may be why CPB is also less frequent on isolated plants. Because L. subgrandis is a secretive insect that seldom flies, 
unless disturbed, it will seek places that offer more refuge from its enemies, shelter from midday sunlight and rain, higher probabilities of finding a mate, and adequate prey for adults, as well as CPB pre-pupae to support the first instar carabid larvae. Thus, to seek clusters of the host plant is advantageous. Adults of the carabid will not move out of an area as long as the plants have an abundant canopy.

Koval (1986) noted this behavior in several carabid predators of the CPB (Carabus hampei Kucst., Poecilus cupreus L., and Pterostichus melanarius Ill.). The numbers of carabids increased (what he calls the numerical strength) with the increase in density of the plants from 50,000 to 70,000 / ha in potato crops in the Soviet Union. Koval explains that the changes in numerical strength of the carabids are related to changes in microclimatic conditions. I add that the availability and diversity of microhabitats is greater, so the insects have more places to hide.

Although $L$. subgrandis is primarily active during the daytime, significant numbers could be found active at night when weather was favorable (no rainfall). Cappaert (1989) mentions that the day and night activity of several Lebinii species from Morelos is distinctive. On the other hand, the R.I. native predator L. grandis is mostly nocturnal, and only a few individuals are active during the day (Groden 1989); burlap trap catches and night counts of $L$. grandis were also affected by weather conditions (high humidity and rainfall). As in the case of $L$ grandis, $L$ subgrandis never was caught in pitfall traps, and when disturbed it dropped to the ground (it seldom flew away to the surrounding weeds). I never captured $L$. subgrandis in the "aerial" pitfall traps. Because L. subgrandis is active both day and night, it is well suited to take advantage of more opportunities to prey and for longer periods of time. L. subgrandis avoids extreme midday heat by seeking refuge under 
stones, in small crevices close to the roots of the plants, in stems or under the leaves of surrounding weeds or in practically any site that offers some shade. It also can keep active during the hottest periods of the day if the CPB's host plant, Solanum sp., has a thick canopy, which in turn mitigates temperature extremes.

From the food preference tests, I could see that $L$ subgrandis did not eat fourth instar CPB larvae under laboratory of field conditions. This is differenct from L. grandis, which feeds on all CPB immature stages (Groden 1989). CPB eggs were the food consumed most frequently by $L$. subgrandis: The preference for eggs has clear advantages in any CPB biological control program. That is, a pair of adult L. subgrandis can consume 42.5 CPB's per day as eggs, but only 0.8 per day as third instars (room temperatures).

Groden (1989) mentions that under laboratory conditions $L$. grandis showed significant difference in consumption of eggs over larvae (but no specific preference for any particular prey stage). However, the difference she mentions is among proportions of food items, which can mask a real preference. In later experiments I expect to establish an actual preference or choice for food based on the biomass of the prey (caloric content or nutritional value), densities of prey and predator, as well as the searching capacity of the predator.

In the field, whenever a $L$. subgrandis adult finds an acceptable prey of any stage, it will remain stationary, eating until the whole prey is consumed. Cappaert (1989) observed that "Lebia beetles" (Lebia sp. and Callida sp. together) readily accepted CPB eggs during all his trials. The mean consumption in his study was $\mathbf{2 0 . 0}$ eggs (range 9 to 37, s.d. $=1.9,10$ carabids). Apparently, the maximum impact of Lebia species on the CPB, including $L$. subgrandis evaluated here, is on the egg stage (Groden 1989, Cappaert 1989). 
Temperature had a prominent effect upon the consumption of RI CPB by $L$. subgrandis: Consumption of CPB immature stages increased with temperature over the range 13 to $28^{\circ} \mathrm{C}$. While the consumption of $L$. subgrandis followed a linear trend between 13 and $28^{\circ} \mathrm{C}$, that of $L$. grandis was quadratic between 15 and $30^{\circ} \mathrm{C}$ (Groden 1989). In further experiments, it will be possible to set the upper temperature limits for $L$. subgrandis feeding. It is possible that this carabid might have some consumption above $34^{\circ} \mathrm{C}$, though less in volume, since I previously mentioned that at high temperatures $\left(33-38^{\circ} \mathrm{C}\right)$ under natural conditions, $L$. subgrandis will stop all activity and retreat to cool and shady areas. L. subgrandis should have no problem at all to adapting to the Rhode Island summer temperatures, as these seldom reach $100^{\circ} \mathrm{F}\left(38^{\circ} \mathrm{C}\right)$, provided the potato plants have enough canopy for shade.

This study indicates that $L$. subgrandis is well adapted to life at warm temperatures. However a different situation is present at lower temperatures where L. subgrandis consumes few prey at $16^{\circ} \mathrm{C}$, and almost none at $13^{\circ} \mathrm{C}$, where it remains nearly motionless.

It is essential that this carabid be able to survive under harsh cold winter temperatures of the Northeast, and resume reproductive activities in the following warm season. At this point, I think that this is the most severe ecological barrier that $L$. subgrandis would face in an attempt to colonize potato crops in the Northeast.

A better understanding of this predator's biology will allow laboratory production of this species using inexpensive methodologies, for purposes of animal release. To date, I have made no attempt to release or evaluate this species in field conditions in Rhode Island. 
Although L. subgrandis refused to prey on species other than L. decemlineata under field conditions, it consumed aphids when offered, and lived on aphids for 67 days in the laboratory. L. subgrandis did not accept any other kind of prey from the five species I offered.

The carabids displayed an interesting behavior when trying to recognize the type of food I put in the dishes. I do not know whether chemicals are used for recognition of the prey or the host plant by the predator. I did, however, observe $L$. subgrandis apparently biting or "tasting" the surface of potato or Solanum sp. leaves before approaching the prey I offered. Also, the insects approached the prey, then stopped, recognized, circled, and left without consuming anything.

Although I will have to try more species of beneficial insects as prey, our preliminary results on host specificity were promising. The R.I. native $L$. grandis (Groden 1989) appears also to be very specific to CPB. Although L. grandis too is able to feed on aphids in the absence of CPB prey, it will not feed on aphids when CPB's are present.

Females from the early summer were able to produce more offspring than females from the late summer; the mating status was not significant in the production of first instar larvae. I think that the differences I found due to mating status are related to conditions other than length of time the female $L$. subgrandis were confined with males. I had females that were never confined with males (i.e., they presumably had mated the previous season) that produced more offspring than the females that were confined with males for 3 days. Also, females from the emergence cages isolated since the first day of capture laid viable eggs. Possibly, females from the late summer can mate but, due to dry conditions in the 
environment, they stop laying eggs and enter a reproductive diapause. They may then enter the soil until conditions are favorable the next year; these females may resume laying eggs the next rainy season. Under laboratory conditions, however, females from the late summer kept in a growth chamber at $25^{\circ} \mathrm{C}$, a photoperiod of L:D 16:8, and enough food, continued laying eggs until December 4th, 1990. Groden (1989) mentions that L. grandis summer adults will oviposit until the following summer. Possibly, she refers to late summer adults. Also, when Hemenway and Whitcomb (1967) could not get $L$. grandis to oviposit after several attempts in the lab, perhaps they had collected prediapausing adults. Prediapausing adults of $L$. subgrandis in this study and $L$. grandis (Groden 1989), can keep active (and still feed on CPB), but will reduce oviposition to a minimum ( $L$. subgrandis) or will stop oviposition ( $L_{\Delta}$ grandis [Groden 1989]). Both species will then overwinter as adults and will resume oviposition the following summer.

The changes in the ovaries of female $L$. subgrandis I observed are related to the oviposition I discussed above. It was during July (females from early summer) that I noted the major production of eggs, although by late July the production of eggs diminished. Most of the females collected in late summer (August and September) had their ovaries "regressed," though some were actively laying eggs until late in the Fall. This is compatible with an hypothesis that females from the late summer might still be mating and, under field conditions, they will retreat to their hiding places already inseminated. Similarly, by late fall, females from the early summer had stopped all reproductive activity.

Although the average survival time for $L$. subgrandis first instar larvae (8.3 \pm 2.5 days) was longer than that of $L$. grandis ( $4.07 \pm 0.14$ days) (Groden 1989), the 
rate of mortality was high by the fourth and fifth days under room conditions. To enhance rearing for this predator, keeping the larvae alive for longer periods of time will be important. L. subgrandis first larvae are strict ectoparasites of CPB pre-pupae and pupae and until an artificial diet is developed, we will be depending on the production of CPB pre-pupae and pupae to rear $L$ subgrandis. Further studies will be needed to assess the influence of time on the ability of $L$. subgrandis first instar larvae to parasitize their host.

L. subgrandis is a subtropical species which will be very difficult to adapt to cold climates. In the early spring of the Northeast, $L$. grandis may forage and be reproductively active at temperatures below $20^{\circ} \mathrm{C}$ (Groden 1989). L. subgrandis, however, had a low $\mathrm{CPB}$ prey consumption at $16^{\circ} \mathrm{C}$, and it could barely eat and move at $13^{\circ} \mathrm{C}$ and below. It is doubtful that this species will be capable of any reproduction at low temperatures.

Results concerning the survival of adult $L$. subgrandis captured in the field are not conclusive at all. Some of the adults used in the experiment were of unknown age. This could be true also for the adults captured in the emergence cages, because as I said, they could have been buried in the soil during the previous dry season. However, the fact that some adults may live up to 3 or 4 under lab conditions, improves chances for reproduction of this carabid in confinement. Later studies with adults emerged in the lab will allow a better measure of adult $L$. subgrandis lifespan. 


\section{SUMMARY}

I investigated the biology of the Mexican carabid Lebia subgrandis Madge, a potential biological control agent of the CPB. I set up field and lab investigations in Mexico in the summer of 1989 and 1990, and lab investigations in Rhode Island in 1988-1990. In 1990, L. subgrandis had two periods of emergence: early July and mid August. The incidence curves between adult CPB's and adult $L$. subgrandis were very similar: Predators were numerically correlated with adult CPB's. When the populations of CPB became very low, the carabids were totally absent within the plots, but not in the surrounding weeds, where I found them easily.

There were also strong positive regressions between the numbers of adult $L$. subgrandis and the totals of each CPB stage for all categories of Solanum sp. plants. The number of predators fluctuated over time but remained correlated with adult CPB's regardless of plant size, foliar density, or plant density. L. subgrandis prefers grouped plants, which offer diversity in microhabitats and attract more CPB's.

L. subgrandis is active day and night if the weather is favorable (no rainfall). It avoids the hottest hours of the day, unless the host plants have a thick canopy that mitigates the high temperatures.

L. subgrandis did not eat fourth instar CPB larvae. CPB eggs were more frequently consumed than CPB larvae (1st through 3rd). Pairs of $L$. subgrandis consumed more than the combined consumption of individual females and males. The preference for eggs is advantageous. However, actual preference should be proved based on caloric content or nutritional value of the prey.

The consumption of CPB immature stages by $L$. subgrandis is temperature dependent: the higher the temperature, the more CPB's consumed for all 
temperatures between 13 and $28^{\circ} \mathrm{C}$. The consumption rate followed a linear trend between 13 and $28^{\circ} \mathrm{C}$ for all CPB stages and $L$. subgrandis sex groupings, with the exception of the males, where consumption of CPB eggs showed no relation to temperature. This carabid may adapt to summer Rhode Island temperatures, but it is not clear that it will survive the winters of the Northeast.

Starved and non-starved $L$. subgrandis ate neither eggs nor larvae of $C$. maculata, an important predator of CPB in the potato fields in Rhode Island. There was also no consumption of eggs or nymphs of Oplomus sp., nor nymphs of a reduviid predator of the $\mathrm{CPB}$. The carabids display an interesting behavior when offered prey other than CPB but generally reject such prey. However, this species accepted a diet of aphids. Further studies will include more species of beneficial insects to prevent any harm from future field releases of the predator.

Summer females produce more offspring than fall females; the mating status was not important. It is possible that mating occurs once, and females are able to store sperm in a spermatheca. Females collected in late summer are able to mate and produce mature eggs (as I observed them in dissected females) but they lay less or none during dry periods in the environment. At the onset of dry periods, females from late summer may enter a reproductive diapause, enter the soil, and resume laying eggs in the next year's rainy season.

A long lifespan will be important to rear the predator under lab conditions. Survival of adult male or female $L$. subgrandis captured in the field is variable. Females live an average of 78.0 days and males live 79.4 days under lab conditions. L. subgrandis is a good candidate to be considered as biological control agent of the CPB in the Northeast U.S. But it is necessary to better understand its biology, 
particularly host specificity and reproductive capacity, to promote field releases. Also, further research may reveal whether this sub-tropical species can survive the low winter temperatures. 


\section{LITERATURE CITED}

Anaya, R.S., and A. Burgos S. 1990. El genero Leptinotarsa Stal. (Coleoptera:Chrysomelidae) en el Estado de Morelos: su diversidad, distribucion y algunas consideraciones sobre sus habitos alimenticios. Boletin Soc. Mex. Entomol. No. 5:9-17.

Anderson, T.E., D.W. Roberts, and R.S. Soper. 1988. Use of Beauveria bassiana for suppression of CPB populations in New York State (Coleoptera:Chrysomelidae). Environ. Entomol. 17(1):140-145.

Anderson, T.E., A.E. Hajek, D.W. Roberts, H.K. Preisler, and J.L. Robertson. 1989. Colorado potato beetle (Coleoptera:Chrysomelidae): effects of combinations of Beauveria bassiana with insecticides. J. Econ. Entomol. 82(1):83-89.

Argentine, J.A., J.C. Marshall, and D.N. Ferro. 1989. Genetics and synergism of resistance to azinphosmethyl and permethrin in the Colorado potato beetle (Coleoptera:Chrysomelidae). J. Econ. Entomol. 82(3):698-705.

Boiteau, G. 1984. Effect of planting date, plant spacing, and weed cover on populations of insects, arachnids, and entomophtoran fungi in potato fields. Environ. Entomol. 13(3):751-756.

Bruneteau, J. 1937. Recherches sur les enemies naturals del doryphore en Amerique. Ann. Epiphyties et Phytogenetique. 3:113-135. 
Campbell, R.K., T.E. Anderson, M. Semel, and D.W. Roberts. 1985. Management of the Colorado potato beetle using the entomogenous fungus, Beauveria bassiana. Am. Pot. J. 62:29-37

Cantwell, G.E., and W.W. Cantelo. 1981. Bacillus thuringiensis a potential biocontrol agent for the Colorado potato beetle. Am. Potato. J. 58:457-468.

Cantwell, G.E., E. Dougherty, and W.W. Cantelo. 1983. Activity of the Beta-exotoxin of Bacillus thuringiensis var. thuringiensis against the Colorado potato beetle (Coleoptera:Chrysomelidae) and bacterial mutagenic response as determined by the Ames test. Environ. Entomol. 12:1424-1427.

Cantwell, G.E., and W.W. Cantelo. 1984. Control of the Colorado potato beetle with Bacillus thuringiensis variety thuringiensis. Am. Potato. J. 61:451-459.

Cappaert, D.L., 1989. Ecology of the Colorado potato beetle in Mexico. M.S. Thesis, Michigan State University, East Lansing.

Casagrande, R.A. 1987. The Colorado potato beetle: 125 years of mismanagement. Bulletin of the Entomological Society of America. Fall 1987:142-150.

Chamboussou, F. 1938. Remarques sur Lebia grandis Hentz. Rev. Zool. Agr. $37: 165-171$. 
Chamboussou, F. 1939. Contribution a l'etude biologique de Lebia grandis Hentz, predateur americain du doryphore. Ann. Epiphyties et Phytogenetique. 5(3): 387-433.

Clark, R.A., R.A. Casagrande, and D.B. Wallace. 1982. Influence of pesticides on Beauveria bassiana, a pathogen of the CPB. Environ. Entomol. 11:67-70.

Cutkomp, L.K., A.G. Peterson, and P.E.Hunter. 1958. DDT-resistance of the Colorado Potato Beetle. J. Econ. Entomol. 51(6): 828-831.

Drummond, F.A., 1986. Biology of Chrysomelobia labidomerae and its potential for biological control of the Colorado potato beetle. Ph. D. Dissertation, Rhode Island, Kingston.

Drummond, F.A., 1988. Spatial pattern analysis of Chrysomelobia labidomerae Eickwort (Acari:Tarsonemina:Podapolipidae) on mexican hosts. Int. J. Acarol. 14:199-207.

Drummond, F.A., R.A. Casagrande, R. Chauvin, T. Hsiao, J.H. Lashomb, P.A. Logan, and T.H. Atkinson. 1984. Distribution and new records of a race of Chrysomelobia labidomerae Eickwort (Acari:Tarsonemina:Podapolipidae) attacking the Colorado potato beetle in Mexico. Int. J. Acarol. 10(3):179-180. 
Drummond, F.A., R.L. James, R.A. Casagrande, and H. Faubert. 1984. Development and survival of Podisus maculiventris (Say) (Hemiptera:Pentatomidae), a predator of the Colorado potato beetle (Coleoptera:Chrysomelidae). Environ. Entomol. 13(5):1283-1286.

Drummond, F.A., P.A. Logan, R.A. Casagrande, and F.A. Gregson. 1985. Host specificity tests of Chrysomelobia labidomerae, a mite parasitic of the Colorado potato beetle. Int. J. Acarol. 11(3):169-172.

Drummond, F.A., and R.A. Casagrande. 1985. Effect of white oak extracts on feeding by the Colorado potato beetle (Coleoptera:Chrysomelidae). J. Econ. Entomol. 78:1272-1274.

Drummond, F.A., R.A. Casagrande, E. Groden. 1987. Biology of Oplomus dichrous (Heteroptera:Pentatomidae) and its potential to control Colorado potato beetle (Coleoptera:Chrysomelidae). Environ. Entomiol. 16(3):633-638.

Drummond, F.A., R.A. Casagrande, and P.A. Logan. 1988. Behavior of Chrysomelobia labidomerae Eickwort parasitizing the Colorado potato beetle. Int. J. Acarol. 14:193-198.

Drummond, F.A., R.A. Casagrande, and P.A. Logan, 1989. Population dynamics of Chrysomelobia labidomerae Eickwort, a parasite of the Colorado potato beetle. Int. J. Acarol. 15:31-45. 
Drummond, F.A., Y. Suhaya, and E. Groden, 1990. Predation on the Colorado Potato Beetle (Coleoptera:Chrysomelidae) by Phalangium opilio (Opiliones:Phalangidae). J. Econ. Entomol. 83(3):772-778.

Ferro, D.N., and W.D. Gelernter 1989. Toxicity of a new strain of Bacillus thuringiensis to CPB (Coleoptera:Chrysomelidae). J. Econ. Entomol. 82(3):750-755.

Forgash, A.J. 1981. Insecticidal resistance of the Colorado potato beetle, Leptinotarsa decemlineata (Say), pp. 34-46 In J.H. Lashomb, R. A. Casagrande [eds.], Advances in Potato Pest Management. Hutchinson Ross, Stroudsburg, Pa.

Forgash, A.J. 1985. Insecticide resistance in the Colorado potato beetle. In Proc. Symp. on the Colorado potato beetle, 18th Int. Congr.Entomol., ed. D.N. Ferro, R.H. Voss. pp. 33-52. Res. Bull. 704. Amherst: Mass. Agric. Exp. Stn.

Galindo, P. F. 1990. Enemigos naturales de Leptinotarsa decemlineata Say (Coleoptera:Chrysomelidae) asociados con Solanum rostratum Dunal. XXV Congreso Nacional de Entomologia, Programa y Resumenes: 13-16 de Mayo de 1990, Oaxaca, Oaxaca, Mexico. pp. 183-184

Gauthier, N.L., R.N. Hofmaster, and M. Senel. 1981. History of Colorado potato beetle control, pp. 13-33 In J.H. Lashomb, R. A. Casagrande [eds.], Advances in Potato Pest Management. Hutchinson Ross, Stroudsburg, Pa. 
Gimingham, C.T. 1950. Colorado Beetle Problem. Research: a journal of science and its applications. 3:310-314.

Grisell, E.E. 1981. Edovum puttleri, n.g.,n.sp. (Hymenoptera:Eulophidae), an egg parasite of the Colorado potato beetle (Chrysomelidae). Proc. Entomol. Soc. Wash. 83(4):790-796.

Groden, E. 1989. Natural mortality of the Colorado potato beetle (Leptinotarsa decemlineata [Say]). Ph. D. Dissertation, Michigan State University, East Lansing.

Groden, E., F.A. Drummond, R.A. Casagrande, and D.L. Haynes. 1990. Coleomegilla maculata (Coleoptera:Coccinellidae): its predation upon the Colorado Potato Beetle (Coleoptera:Chrysomelidae) and its incidence in potatoes and surrounding crops. J. Econ. Entomol. 83(4):1306-1315.

Hajek, E.A., R.S. Soper, D.W. Roberts, T.E. Anderson, K.D. Biever, D.N. Ferro, R.A. LeBrun, and R.H. Storch. 1987. Foliar application of Beauveria bassiana (Balsamo) Vuillemin for control of the Colorado Potato Beetle,Leptinotarsa decemlineata (Say) (Coleoptera:Chrysomelidae): An overview of pilot test results from the Northern United States. Can. Ent. 119(11):959-974.

Hare, J.D., P.A. Logan, and R.J. Wright. 1983. Suppression of Colorado potato beetle, Leptinotarsa decemlineata (Say) (Coleoptera:Chrysomelidae) populations with antifeedant fungicides. Environ. Entomol. 12:1470-1477. 
Hare, J.D. 1984. Suppression of the Colorado potato beetle, Leptinotarsa decemlineata (Say) (Coleoptera:Chrysomelidae) on solanaceous crops with a copper-based fungicide. Environ. Entomol. 13(4):1010-1014.

Hare, J.D. 1990. Ecology and management of the Colorado potato beetle. Annu. Rev. Entomol. 35:81-100.

Harris, C.R., and Svec H.J. 1981. CPB resistance to carbofuran and several other insecticides in Quebec. J. Econ. Entomol. 74:421-424.

Hostounsky, Z. 1984. Production of microsporidia pathogenic to the Colorado Potato Beetle (Leptinotarsa decemlineata) in alternate hosts. J. Invertebrate Pathol. 44:166-171.

Idoine, K, and D.N. Ferro. 1989. Diurnal timing of ovipositional activities of Edovum puttleri Grisell (Hymenoptera:Eulophidae), an egg parasitoid Leptinotarsa decemlineata (Say) (Coleoptera:Chrysomelidae). Environ. Entomol. 19(1):104-107.

Ignoffo, C.M., C. Garcia, and M. Kroha. 1982. Susceptibility of the Colorado Potato Beetle Leptinotarsa decemlineata to Bacillus thuringiensis. J. Invertebrate Pathol. 39:244-246.

Ignoffo, C.M., C. Garcia, and M. Kroha. 1983. A leaf surface treatment bioassay for determining the activity of conidia of Beauveria bassiana against Leptinotarsa decemlineata. J. Invertebrate Pathol. 41:385-386. 
Jansson, R.K., J. Lashomb, E. Groden, and R. Bullock. 1987. Parasitism of Leptinotarsa decemlineata by Edovum puttleri (Hymenoptera:Eulophidae) in different cultivars of eggplant. Entomophaga 32:503-510.

Keppel, G. 1982. Design and analysis, a researcher's handbook. 2nd ed. Prentice-Hall, Inc., Englewood Cliffs, New Jersey. 669 pp.

Koval, A.G. 1986. Predatory Carabidae are entomophagous of CPB. Moskva, Ministerstvo Sel'skogo Khoz-i-a-istva SSSR. 11:45-46.

Lashomb, J., D. Krainacker, R.K. Jansson, Y.S. Ng, and R. Chianese. 1987a. Parasitism of Leptinotarsa decemlineata (Say) eggs by Edovum puttleri Grissell (Hymenoptera:Eulophidae): effects of host age, parasitoid age, and temperature. Can. Entomol. 119:75-82.

Lashomb, J., Y.S. Ng, R.K. Jansson, and R. Bullock. 1987b. Edovum puttleri (Hymenoptera:Eulophidae), an egg parasitoid of Colorado potato beetle (Coleoptera:Chrysomelidae): development and parasitization on eggplant. J. Econ. Entomol. 12:907-910.

Logan, P.A., R.A. Casagrande, T.H. Hsiao, and F.A. Drummond. 1987. Collections of natural enemies of Leptinotarsa decemlineata (Coleoptera:Chrysomelidae) in Mexico. 1980-1985. Entomophaga 32(3):249-254. 
Loria, R., S. Galaini, and D.W. Roberts. 1983. Survival of inoculum of the entomopathogenic fungus, Beauveria bassiana as influenced by fungicides. Environ. Entomol. 12:1724-1726.

Madge, R.B. 1967. A revision of the genus Lebia Latreille in America North of Mexico (Coleoptera:Carabidae). Quaestiones Entomologicae. 3:139-242.

MINITAB INC. 1985. MINITAB Handbook, Release 6, Pennsylvania State University.

Ruberson, J.R., M.J. Tauber, and C.A. Tauber. 1988. Reproductive biology of two biotypes of Edovum puttleri a parasitoid of Colorado potato beetle eggs. Entomol. Exp. Appl. 46:211-219.

Samsinakova, A., S. Kalalova, V. Vlcek, and J. Kybal. 1981. Mass production of Beauveria bassiana for regulation of Leptinotarsa decemlineata populations. J. Invertebrate Pathol. 38:169-174.

SAS INSTITUTE. 1990. SAS User's guide: statistics. SAS Institute. Cary, NC.

Sorokin, N.S. 1981. Ground Beetles (Coleoptera:Carabidae) as natural enemies of the Colorado Beetle Leptinotarsa decemlineata Say. Entomol. Rev. $60(2): 44-52$. 
Tamaki, G., and B.A. Butt. 1978. Impact of Perillus bioculatus on the Colorado potato beetle and plant damage. United States Department of Agriculture. Technical Bulletin no. 1581.

Tamaki, G., R.L. Chauvin, and A.K. Burditt. 1983a. Field evaluation of Doryphorophaga doryphorae (Diptera:Tachinidae) a parasite, and its host the CPB (Coleoptera:Chrysomelidae). Environ. Entomol. 12(1):386-389.

Tamaki, G., R.L. Chauvin, and A.K. Bursitt. 1983b. Laboratory evaluation of Doryphorophaga doryphorae (Diptera:Tachinidae), a parasite of the CPB (Coleoptera:Chrysomelidae). Environ. Entomol. 12(3):390-392.

Tower, W.L. 1906. An investigation of evolution in Chrysomelid beetles of the genus Leptinotarsa. Carnegie Institution of Washington. Publication No. 48. 320 pp.

Trouvelot, B. 1931. Recherches sur les parasites et predateurs attaquant le doryphore en Amerique du nord. Ann. Epiph. 6:408-445.

Watt, B.A., and R.A. LeBrun. 1984 Soil effects of Beauveria bassiana on pupal populations of the Colorado potato beetle. Environ. Entomol. 13:15-18.

Zehnder, G.W., and W.D. Gelernter. 1989. Activity of a new strain of Bacillus thuringiensis against the Colorado potato beetle (Coleoptera:Chrysomelidae): relationship between susceptibility and life stage. J. Econ. Entomol. 12:756-761. 